\title{
Innovaciones de raíz helenística en el armamento y tácticas de los pueblos Ibéricos desde el siglo III a.C.*
}

\author{
Fernando Quesada Sanz \\ Universidad Autónoma de Madrid
}

\section{Resumen}

A partir de mediados del s. III a.C. se introdujeron novedades en la panoplia de los pueblos ibéricos del Levante, Sureste y Mediodía peninsular. En concreto, escudos ovales, cascos metálicos y espadas de hoja recta. Sin embargo, nunca llegaron a sustituir por completo la panoplia tradicional basada en el escudo circular, casco de cuero y falcata, excepto quizá en unidades que servían de modo más o menos permanente en ejércitos cartagineses. En efecto, durante este periodo tropas iberas fueron crecientemente empleadas por Cartago en sus ejércitos de corte helenístico, y luego por los romanos, en funciones de infantería de línea (de uso dual), e infantería ligera, además de caballería.

Sin embargo, la adopción de armamento de influencia helenístico, y su participación en ejércitos complejos, no parecen haber alterado en lo esencial ni las formas ibéricas de entender la guerra, ni las tácticas ni incluso la panoplia, salvo cuando combatían al servicio de potencias extranjeras.

En cuestiones militares, entre los siglos IV y II a.C. el mundo ibérico vió como aumentaban, en lugar de limarse, las diferencias que le separaban del Mediterráneo centro-oriental, cuyo desarrollo militar se aceleró considerablemente durante el periodo helenístico.

Palabras clave: Cultura Ibérica. Periodo Helenístico. Guerras Púnicas. Armamento. Táctica. Guerra.

\section{Abstract}

Since the second part of the third century BC, new types of weapons were introduced in the Iberian panoply in the Eastern and Southern regions of the Peninsula. However, these oval shields, bronze Montefortino helmets, and straight swords, never really displaced the traditional weaponry based on the round shield, leather helmet and curved falcata, except probably in those units serving under Carthaginian standards on a more or less permanent basis. During this period lberians were increasingly being used by the Carthaginians, (as allies, subjects or mercenaries) in their hellenistic-type armies, and later by the Romans, as either line (dual-purpose) or light infantry, and as cavalry.

However, neither the adoption of hellenistic-type weapons, nor the integration of lberian contingents in these complex armies, seem to have altered the basic Iberian approach to warfare, tactics and arms, except when they were fighting for foreign powers

In military matters, it seems that between the fourth and the second centuries B.C., the Iberian Culture lagged behind the new and striking developments that took place in the Central and Eastern Mediterranean during the Hellenistic Period. It also seems that the gap in complexity and sophistication widened rather than narrowed during this period.

Keywords: Iberian Culture. Hellenistic Period. Punic Wars. Weapons. Tactics. Warfare.

Hace ya algunos años M. Almagro-Gorbea (1990) defendía que "plus qu’une période hellénisti- que propre, dans la culture ibérique il faut considérer un processus d'acculturation hellénistique qui pê̂t être

\footnotetext{
* Trabajo realizado en el marco del Proyecto "La imagen de las armas en la Iberia prerromana" (BHA 2001-0187).
} 
défini comme un ensemble de phénomenes d'assimilation et d'influences provenant du monde hellénistique. Ces phénomènes de difussion ont été assimilés par la société et la culture ibérique sur un substrat formé par un processus d'acculturation plus ancien...”. Quince años después, y si aceptamos el término 'aculturación' en un sentido muy lato y vago de influjo cultural, esta cuestión no es ya objeto real de debate. ${ }^{1}$ Pero si tratamos de precisar el grado en que esa asimilación penetró en lo profundo de la fábrica social ibérica, las discrepancias entre estudiosos se hacen mucho mayores.

\section{RASGoS CARACTERÍSTICOS DE LA GUERRA EN EL MUNDO HELENÍSTICO (C. 323-C. 30 A.C.) Y DEL EJÉRCITO CARTAGINÉS DURANTE la Segunda Guerra Púnica (237-202 A.C.).}

Partiendo de la base indiscutible de que las estruturas militares de una sociedad mediterránea en la Edad del Hierro fueron parte esencial de esa fábrica social, pretendemos examinar en este trabajo hasta qué punto algunas de las grandes innovaciones en armamento, tácticas y concepción de la guerra que se produjeron en el mundo helenístico entre finales del s. IV a.C. y mediados del I a.C., encontraron acogida en la Cultura Ibérica del lejano Occidente, a través del mercenariado en Sicilia y en especial de los contactos con el ejército cartaginés primero, y el romano después. En cierto modo, este trabajo continúa para los siglos III-I a.C. otro realizado hace ya algunos años para el periodo anterior al s. III a.C. en el que examinábamos el -a nuestro juicio muy reducido- papel que los mercenarios ibéricos pudieron haber ejercido como 'agentes de helenización' (Quesada, 1994). ${ }^{2}$ Evidente-mente, los resultados de esta aproximación son relevantes no sólo en la estricta esfera militar, sino que afectan

\footnotetext{
1 Por oposición a un concepto estricto según el que 'aculturación', por oposición a la mera difusión cultural, equivaldría a una transformación profunda de la sociedad receptora, que alteraría significativamente sus estructuras sociales y económicas (caso por ejemplo de Sicilia en época arcaica), y no sólo adoptaría epidérmicamente algunos elementos de la cultura emisora, (ver al respecto, González Wagner 1992:94;1993; para nuestra postura, Quesada 1994b:115, n. 176). En sentido estricto, no hubo “aculturación” helénica o helenística en Iberia.

2 Escribíamos en 1994 al final de aquel trabajo: "Otra cuestión, que exigiría un estudio independiente, es la de la 'helenistización' de Iberia, que la final se confundirá con el proceso de 'romanización'. Este fenómeno exigió la presencia mucho más sistemática de Cartago a partir del desembarco en Gadir de Amilcar en 237 a.C.; a partir de este momento hallamos un contacto mucho más intenso
}

a la naturaleza de la comprensión de los procesos globales de cambio cultural en la Baja Epoca de la Cultura Ibérica, y en particular a la siempre presente cuestión del tipo y grado de 'helenización' y 'helenistización' cultural (Almagro Gorbea, 1990).

En primer lugar resultará útil definir sucintamente cual fue la naturaleza de éstas innovaciones helenísticas, como paso previo para examinar cuáles de ellas, y en qué grado, pudieron afectar al mundo ibérico. Dado que la bibliografía sobre el mundo militar helenístico es colosal, y puesto que ahora nos interesan sólo las tendencias generales, podremos resumirlas convenientemente en un cuadro (Figura 1).

En segundo lugar, y dado que el mundo ibérico no entró en contacto militar directo con las potencias helenísticas, mientras que sí lo estuvo con el Mediterráneo central, y en particular con los ejércitos cartagineses en los que tropas ibéricas venían sirviendo durante siglos, convendrá recordar que en época de los Barca la organización militar cartaginesa se había transformado sustancialmente desde el ejército ciudadano más antiguo (como acertadamente recalcaba no ha mucho Carlos González Wagner, 1994) y había adoptado rasgos helenísticos bien definidos aunque con una fase 'protohelenística' definida por la multietnicidad (González Wagner, 1994:834). Si utilizamos el mismo cuadro de la Figura 1 y examinamos las fuentes disponibles sobre el ejército cartaginés (uno de los más detallados análisis sigue siendo el de Gsell, 1920:331-435), podemos concluir con la gran mayoría de los investigadores $^{3}$ que en efecto los ejércitos de época anibálica tienen muchos de los rasgos característicos de un ejército helenístico, y en particular el que Aníbal, líder carismático de corte helenístico, ${ }^{4}$ llevó a Italia. Como escribe Barreca (1983-84:67): “Gli

pero también, enseguida, más brutal. El estallido de la Segunda Guerra Púnica puso en marcha alteraciones notables desde el momento en que Iberia dejó de ser una región relativamente apartada para entrar en el juego de las grandes potencias y finalmente caer en la órbita de la expansiva República Romana” (Quesada, 1994:231).

3 Especialmente Santosuosso (1997:170); Barreca (198384:67); también Le Bohec, (1996:39-40); Brizzi, (1995:309-311) González Wagner (1994:834-835); Huss (1993: 113 ss. y 319); Picard, (1958:196, 201, 211); Gsell, (1920:394); con matices, Goldsworthy (2000:30 ss.); Brizzi, (1995:314).

4 Polibio 11,19,3-5; Livio 21,4; ver Hoyos (2003:2-3); Brizzi, (1995:312-313); Barceló, (2000:48-49); Lévêque (1985:274-275); Gsell, (1920:432); Almagro Gorbea, (1990:114 y n. 34). 


\begin{tabular}{|c|c|c|}
\hline NIVEL & RASGOS CARACTERÍSTICOS & FRENTE A (en la fase anterior)... \\
\hline \multirow{4}{*}{ ARMAMENTO } & $\begin{array}{l}\text {-Tendencia a la estandarización y } \\
\text { fabricación en masa.* }\end{array}$ & Producción artesanal \\
\hline & -Resurgir de la armadura metálica & Tendencia a armadura textil \\
\hline & -Pica en infantería y caballería & Lanza en infantería, jabalina en caballería \\
\hline & -Extensión del escudo oval & Escudo circular predominante \\
\hline \multirow{8}{*}{ TIPOS DE TROPA } & -Variedad y especialización. & -Primacía infantería pesada \\
\hline & $\begin{array}{l}\text {-Tendencia a la profesionalización y } \\
\text { mercenariado * }\end{array}$ & -Milicias \\
\hline & -Importancia de la caballería pesada & -Escasa importancia de la caballería \\
\hline & -Falange falangita y hoplita & -Falange hoplita \\
\hline & -Infantería de uso mixto & -No existe apenas infantería de uso dual \\
\hline & $\begin{array}{l}\text {-Importancia de la infantería ligera } \\
\text { especialista, casi siempre mercenaria* }\end{array}$ & -Escasa infantería ligera especialista \\
\hline & -Armas exóticas (elefantes, artillería) & -No hay armas 'exóticas' ni artillería \\
\hline & -Complejidad étnica de los ejércitos. & $\begin{array}{l}\text {-Generalmente, homogeneidad } \\
\text { étnica de los ejércitos }\end{array}$ \\
\hline \multirow{4}{*}{ TÁCTICA } & -Coordinación interarmas & -No hay apenas cooperación interarmas \\
\hline & -Operaciones todo tiempo * & -Normalmente guerra en primavera \\
\hline & -Tretas complejas, reservas & -Emboscadas y tretas sencillas \\
\hline & -Asedios complejos & -Apenas hay asedios y son sencillos. \\
\hline \multirow{2}{*}{ MANDOS } & $\begin{array}{l}\text {-Profesionalización en el generalato y } \\
\text { en los rangos bajos. }\end{array}$ & -Amateurismo en los mandos \\
\hline & $\begin{array}{l}\text {-Liderazgo por carisma militar } \\
\text { ganado en el campo de batalla. }\end{array}$ & $\begin{array}{l}\text {-Liderazgo por linaje o } \\
\text { por elección política }\end{array}$ \\
\hline \multirow{4}{*}{ LOGíSTICA } & $\begin{array}{l}\text {-Logística compleja, en parte } \\
\text { provista por el Estado.* }\end{array}$ & $\begin{array}{l}\text {-Logistica elemental, } \\
\text { básicamente individual. }\end{array}$ \\
\hline & $\begin{array}{l}\text {-Complejidad de pagos a grandes } \\
\text { contingentes mercenarios. }\end{array}$ & -Pago sobre todo a ciudadanos \\
\hline & $\begin{array}{l}\text {-Guarniciones permanentes } \\
\text { habituales con mercenarios. }\end{array}$ & $\begin{array}{l}\text {-Guarniciones permanentes raras, } \\
\text { normalmente con ciudadanos. }\end{array}$ \\
\hline & $\begin{array}{l}\text {-Asentamientos militares con concesiones } \\
\text { de tierra entregados por el estado. }\end{array}$ & -Soldados propietarios \\
\hline
\end{tabular}

(*) Este cuadro, como cualquier simplificación, tiende a enmascarar los procesos en el tiempo. En Grecia central desde la guerra del Peloponeso (segunda mitad del s. V) y en Siracusa durante el s, IV.a.C. se venían anunciando de manera más o menos tímida aspectos que se generalizarían durante época helenística (señalados con *)

Referencias Bibliográficas generales de utilidad: Tarn 1930, Griffith 1935; Lévêque 1985; Sekunda 1989; 1994; 1995, 2001; Yalichev 1997.

Fig. 1. Rasgos característicos de la guerra en el mundo helenístico. 
storici moderni definiscono ellenistici gli esserciti annibalici. La definizione è certamente accettabile, nel senso che tali esserciti e quello greco-macedonici del sec. III a.C. ebbero gli stessi corpi (fanteria leggera, fanteria pesante, cavalleria, elefanti) ed analoghe strutture... Anche il rapporto proporzionale tra fanteria e cavalleria e la grande importanza data a quest'ultima da Annibale, troveno significativo riscontro del mondo greco-macedone...”. Ahora bien, todo indica que los ejércitos cartagineses de Hispania, aún conservando muchos de los rasgos antes citados (complejidad en la composición táctica, étnica, empleo sistemático de caballería, infantería de uso mixto e infantería ligera) carecen del delicado equilibrio de fuerzas y la profesionalidad del ejército de Italia, y sobre todo del liderazgo único de un Aníbal, lo que debilitó considerablemente su eficacia; además, su composición parece haber sido mucho más 'local', lo que debilita sus similitudes con el ejército de Aníbal.

Ahora bien, el que los ejércitos cartagineses integraran mercenarios, adoptaran una estructura táctica de tipo helenístico, y contaran con líderes carismáticos rozando incluso la divinización, no implica como se ha sugerido en alguna ocasión (Almagro Gorbea 1990:114) que esos fenómenos se transmitieran a la sociedad ibérica y la alteraran -aculturaran- sustancialmente: simplemente implican que el mundo cartaginés estaba helenistizado, no que el ibérico lo estuviera también; haría falta bastante tiempo, bastante intensidad de influencia, y un nivel de estructuración social muy relevante en la soeiedad receptora para que ello se produjera: volveremos sobre ello, limitándonos al aspecto militar. ${ }^{5}$

\section{INNOVACIONES EN EL ARMAMENTO IBERICO DESDE S. III A.C. Y SU RELACIÓN CON LA 'GUERRA DE ANÍbAL'.}

En una franja temporal que es difícil precisar demasiado, pero que sin duda abarca parte de la segunda mirad del s. III a.C., esto es, el periodo de creciente y masiva implantación militar cartaginesa bárquida en Iberia, se produjeron en el

\footnotetext{
5 Para el conjunto, una de las mejores síntesis sigue siendo la ya añeja y discutible, pero perceptiva, de Almagro Gorbea (1990), retomada y amplificada recientemente (Almagro Gorbea 1996:107 ss.).

6 Quesada (1992); García Mauriño (1993), y sobre todo Quesada (1997a:554 ss.;1997c). Posteriormente, ver García y Rubert (2000).

7 Incluyendo el polémico casco de la Sep. 4F-2 de Pozo Moro, para el que siempre hemos defendido una data-
}

armamento ibérico una serie de innovaciones que son muy significativas. Básicamente, afectaron a la protección de los guerreros, aunque sin desplazar las armas tradicionales. Nos referimos a la introducción amplia del escudo oval (scutum

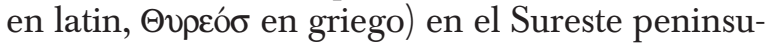
lar y Andalucía, además de, probablemente, en la Meseta; y del casco de bronce de origen itálico llamado comunmente 'Montefortino' o de 'gorra de jockey'. A estos nuevos elementos cabe añadir el resurgir de la espada de hoja recta de doble filo y punta derivada de viejos modelos de La Téne, probablemente importada de la Meseta, y que será el origen de la espada romana republicana tardía, el gladius hispaniensis. El escudo oval y el casco de bronce operaban con ventaja sobre la caetra circular -incluso sobre las grandes, mayores de $65 \mathrm{~cm}$. de diámetro- y el capacete de cuero en tipos de guerra más intensos, donde el choque de grandes formaciones de infantes en batalla campal se iba convirtiendo en la norma; nos referimos a las circunstancias de las Guerras Púnicas. Volveremos más adelante sobre el tema.

Por lo que se refiere al casco de tipo 'Montefortino' y sus variantes, varios estudios recientes nos eximen de insistir en detalle en las dos cuestiones claves para lo que ahora nos interesa: la distinción de las diferentes variantes y la fecha de su introducción. ${ }^{6}$ Aparte de un muy reducido número de cascos de hierro de tipo celta lejanamente emparentados con el tipo, la inmensa mayoría de los cascos 'de gorra de jockey' en Iberia/Hispania pertenecen a cuatro grupos discernibles por su tipología, y también por su distribución geográfica y cronología. En primer lugar, cascos hallados en el Sureste peninsular en contextos indígenas -normalmente necrópolis- fechados en todos los casos en que ha sido posible determinarlo a partir de fines del s. III a.C. (Quesada 1997a:560), a menudo inutilizados y casi siempre despojados de carrilleras. ${ }^{7}$ Esta serie es la que marca la aparición de estos cascos entre tropas indígenas en Iberia, junto con su clara representación en la cerámica del estilo de Liria

ción de fines del s. III en adelante, y no del s. IV como su aparente asociación a un kantharos de barniz negro ático parecía probar (Quesada, 1997a:562; 1997c:156 contra García Mauriño 1993:115, nada convencido de su propia posición). El epígrafe romano -y no iberode un tal MVLVS punteado sobre el guardanuca (de Hoz, 1994) certifica su origen como probable botín de guerra. 
(ver más abajo para la firme datación de este estilo a partir de la Segunda Guerra Púnica) (Quesada 1997a:Fig. 323, aquí Figura 2). Los otros tres grupos de cascos se asocian a la penetración romana en el nordeste y Meseta (ss. II-I a.C.) y Meseta y Suroeste (s. I a.C.), junto con las imitaciones galaicas (fin s. I a.C.-s. I d.C.) y por tanto no son relevantes para nuestra discusión, salvo en el detalle de que no todos los cascos de este tipo genérico son iguales, ni por tipología, ni por cronología ni por distribución, y que por tranto hay que ser muy cuidadoso a la hora de no mezclarlos (Quesada 1997c). Los cascos asociados a contextos ibéricos son sumamente minoritarios en yacimientos como Cabecico del Tesoro, Cigarralejo, Ceal y otros, y muestran que este tipo de casco, crecientemente popular, no fue sin embargo introducido de modo masivo en época anibálica y posterior. Coincidimos plenamente con Yann Le Bohec (1996:43) en que estos cascos no sólo se asocian en el s. III a.C. a los ejércitos romanos, sino que 'des mercenaires au service de Carthage ont dû porter des couvre-chefs de ce type". Con el casco Montefortino ocurría probablemente en Cartago lo que veremos en seguida con más claridad en el caso del escudo oval: su origen itálico no impedía su existencia, y quizá incluso su generalización, entre las tropas mercenarias e incluso las ciudadanas, ya que se trataba de un modelo a la vez abundante, barato y eficaz. ${ }^{8}$ Algún testimonio iconográfico recogido por M. Fantar (1993:II, p. 99-100) apunta en la misma dirección marcada por Le Bohec; sería pues factible que el casco Montefortino se introdujera -al menos al principio- en Iberia vía intermediarios púnicos o mercenarios ibéricos al servicio cartaginés.

Tampoco vamos a insistir ahora en otra de las innovaciones que experimenta la panoplia ibéri-

\footnotetext{
8 De hecho, a partir del s. II y durante todo el s. I a.C. el casco Montefortino y sus variantes evolucionadas (Buggenum, etc.) se convirtió en el más extendido en el Mediterráneo, desde Galicia al Próximo Oriente ( $c f$. especialmente Raev, Simonenko, Treister (1991); Robinson, (1975); Schaaff, (1988); Völling, (1997); Feugère, (1994:37 ss. y p. 81).

9 Para un análisis minucioso de esta cuestión, que nos
}

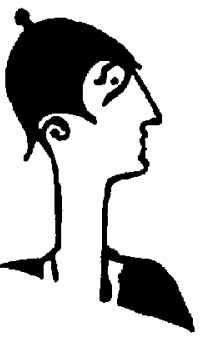

a

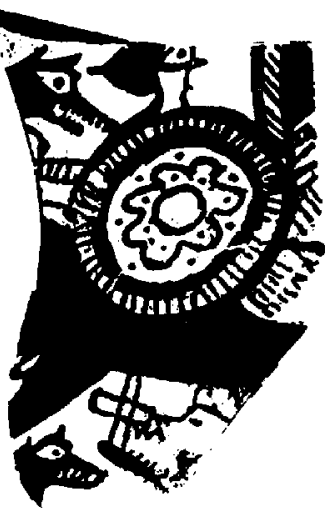

b

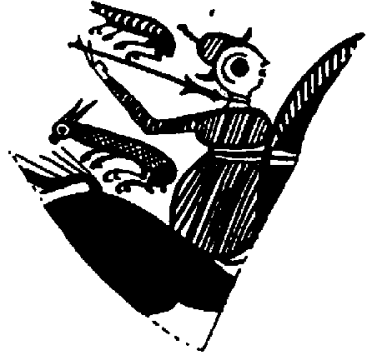

C

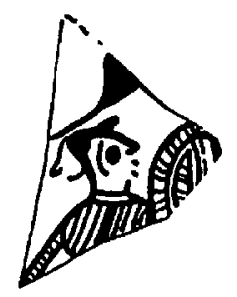

d
Fig. 2. Representaciones de cascos de tipo Montefortino en cerámica figurada ibérica.

ca, en este caso no por influencia mediterránea sino del mundo celtibérico: la aparición -posiblemente ya desde la segunda mitad del s. IV a.C.de espadas de hoja recta del tipo genérico de La Tène I (aunque modificadas de acuerdo con los gustos locales) e incluso de algunos puñales de empuñadura dobleglobular típicamente celtibéricos. Por lo que se refiere a las espadas, que a nuestro juicio serían las adoptadas por los romanos como su gladius hispaniensis, ${ }^{9}$ no parecen haber sustituido, ni siquiera desplazado, a la falcata, salvo quizá en el ejército de Aníbal (Polibio, 3, 114 parece referirse al empleo por las tropas hispanas de Aníbal de espadas rectas punzantes y cortantes frente a las galas tardías sólo tajantes).

En cuanto al puñal dobleglobular, recientes hallazgos en las zonas valencianas lindantes con

exime de entrar aquí en mayores detalles, ver Quesada (1997a:260-273; 1997d); con posterioridad, también Rapin, (2001b) con puntos de vista discordantes, tendentes a rechazar el origen hispano del gladius hispaniensis (sic). También Connolly (1997, aceptando nuestros puntos de vista en p. 56). Finalmente, Horvat (1997); Istenic, (2000); Smit, Pelicon, (2000). 
la meseta y en Catluña hacen aparecer puñales biglobulares en contextos ibéricos tardíos, aunque en el caso catalán del Turó del Vent, al menos, parecen haber sido en forma de trofeos enclavados en santuarios o capillas. ${ }^{10}$

Esas armas ofensivas plantean interrogantes respecto a su extensión real en época ibérica a partir del final del s. III a.C. Aunque desde luego encajan mejor con el armamento y las pautas tácticas características de la guerra en el Mediterráneo central desde ese periodo, la escasez de datos hace todavía poco prudente utilizarlas en demasía en nuestra argumentación, aunque su mera existencia la apoya.

Mucha más atención dedicaremos en esta ocasión al escudo oval, sobre el que sigue existiendo cierta confusión terminológica y tipológica, en particular en lo referido al momento, causas y causante de su introducción en Iberia, que como veremos es mucho más complejo de lo que se viene creyendo desde el artículo fundamental de J. Cabré (1939-40).

Con todo, el escudo oval en términos genéricos ha sido objeto de estudios importantes recientes y desde ópticas diferentes por diversos autores $^{11}$, lo que nos exime de entrar en detalles sobre su origen último (posiblemente celta noritálico), técnica de construcción, difusión y variantes. ${ }^{12}$ Es cierto que el escudo oval fue en la Edad del Hierro el tipo más característico de los pueblos que denominamos 'célticos' en sentido lato, en una versión con el cuerpo plano: pero también lo fue de muchos pueblos itálicos, en su versión plana en Etruria (tipo $\mathrm{C}$ de Eichberg, 1987:Beil. I), y luego en una versión curvada en forma de teja, variante que según Livio protegía mucho mejor al combatiente que el plano (Livio $38,21,4)$, y que al parecer se introdujo en Roma a lo largo de la Segunda Guerra Púnica (Eichberg, 1987:190191, Tipo A) (Figura 3). ${ }^{13}$ Así pues, el escudo oval no fue sólo celta, sino también etrusco e itálico, y luego, en una nueva variante, también romano. ${ }^{14}$ Más importante aún para el problema que tratamos aquí, el escudo

\footnotetext{
10 Sobre los puñales de La Peladilla, Punto de Agua y el Molón en Valencia, Quesada (1997a:294) con las referencias bibliográficas oportunas. Sobre los del Turó del Vent, ver además Sanmartí (1994); Rovira, (1999).

11 Stary (1981b), Briquel (1986), Eichberg (1987), Rapin (Brunaux y Rapin, 1988) (2001) y nosotros mismos (Quesada, 1997a:532-547).

12 Sobre la construcción, materiales, peso, etc. ver Quesada (1997a:534 ss.).

13 Insistiendo en la diferencia plano/curvo y las dificul-
}

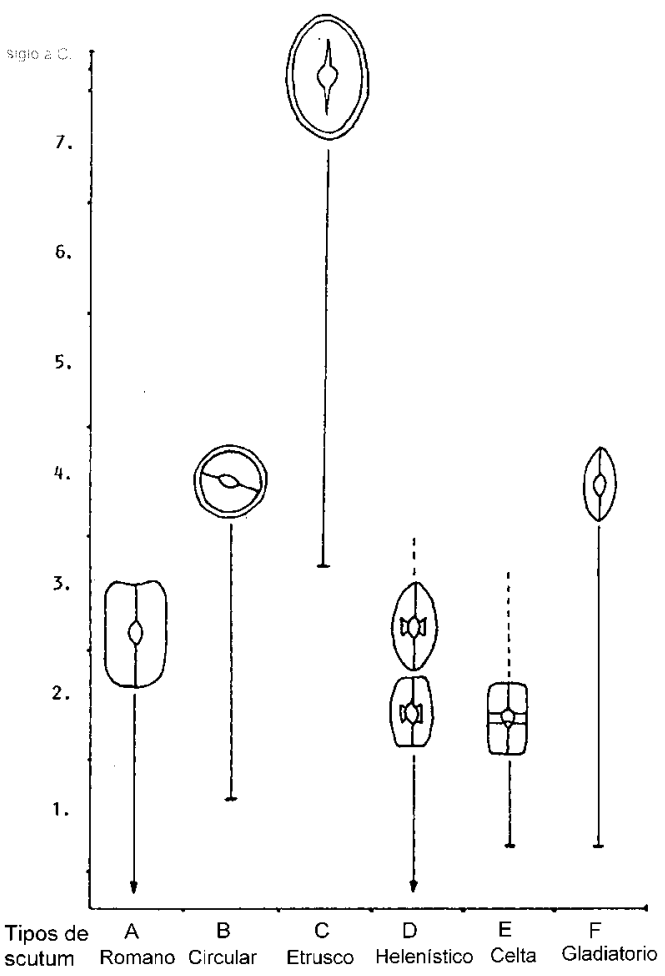

Fig. 3. Tipos y cronología del scutum (a partir de Eichberg 1987).

oval fue también muy empleado al menos desde principios del s. III a.C. por muchas tropas griegas, quienes quizá lo tomaran de los gálatas en sus viejas invasiones, pero quizá desde mucho antes. ${ }^{15}$ Por ejemplo, las tropas griegas de la Liga Aquea combatían en falange, pero a fines del s. III a.C. en lugar del aspis hoplita empleaban el escudo oval, y Filopemen les convenció para que adoptaran el aspis (Pausanias, 8,50.1; Plutarco, Filopemen, 9). Con el tiempo, el thureos no desplazó por completo al aspis, pero llegó a ser el arma estándar de los peltastas, una infantería capaz tanto de combatir en orden cerrado como en guerrilla, que poco a poco abandonó la pelta en favor del escudo oval (Snodgrass, 1967:123); de hecho el término thureophoroi llegó con el tiempo a designar a los mercenarios helenísticos en general armados con este escudo ( $c f$. Polibio

tades de identificación en la iconografía, Rapin (2001:282).

14 En este sentido, pues el artículo señero de J. Cabré (1939-40) debe considerarse ya obsoleto.

15 Por ejemplo la del galo Brenno en 279 a.C. Si embargo, es posible que al menos los aqueos del Peloponeso emplearan el escudo oval independientemente desde una antigüedad más remota (Snodgrass, 1964:61, Anderson, 1970:14). 
10,29,6), como muestran por ejemplo las estelas sidonias y otros monumentos del Mediterráneo oriental (por ejemplo, Figuras 4 y 5) (Sekunda 2001). Esta precisión es importante, porque prueba que al tiempo que los romanos empleaban el escudo oval curvo (Minerva de la muralla de Tarragona hacia fines del s. III, monumento de Emilio Paulo en Delfos en la primera mitad del s. II en adelante, etc.) su uso estaba también extendido por el Mediterráneo oriental. En conjunto, y en sus distintas variantes, el escudo oval aparece desde el Sur de la Península Ibérica hasta Dinamarca, y desde Irlanda a Egipto y Mesopotamia (Stary, 1981b:287), pero esto no significa que todos estos escudos sean iguales: ya Eichberg (1987) distinguía seis grupos (A-E) que se solapan en el tiempo, (ver Figura 3), tipos que él denomina "Romano" (A), Redondo (B), etrusco $(\mathrm{C})$, Helenístico $(\mathrm{D})$, Céltico $(\mathrm{E})$ y gladiatorio (F). A menudo es difícil distinguir entre el tipo etrusco y el helenístico (1987:219), y en realidad la denominación de los tipos que propone no se puede equiparar con los usuarios: "por ejemplo, los mercenarios celtas en los ejércitos helenísticos se servían del scutum allí en uso, que hay que distinguir del arma usada al norte de los Alpes" $(1987: 218-219) .{ }^{16}$

Una cuestión clave pero difícil de determinar es si los ejércitos cartagineses (esto es, las tropas africanas ciudadanas o las libias) emplearon el escudo oval. Es improbable que ello ocurriera antes de la Segunda Guerra Púnica, cuando el escudo normal era citrcular de gran tamaño, atestiguado por fuentes e iconografía (Fantar, 1993,vol. II, 94-95) aunque muy probablemente era conocido a través de los mercenarios de origen galo o incluso del nordeste de la Península Ibérica (infra). En el ejército de Aníbal, por el contrario, el escudo oval era un arma común, pero probablemente más por influencia romana

\footnotetext{
16 Siguiendo aún a Eichberg, el scutum fue estrictamente itálico hasta principios del s. IV a.C., cuando se extendió a través de la llanura del Po y hacia el territorio de La Tène (1987:183 184, 217218); Stary, sin embargo, sobre la base de las representaciones de scuta en una vaina de espada, lleva la difusión del scutum al siglo $\mathrm{V}$ a.C. (Stary, 1981b:294), quizá en su segunda mitad -(véase la vaina en S. Moscati, ed. (1991:166)-, aunque en todo caso acepta el origen itálico. La diferencia de matiz es que Stary cree que el resurgimiento del scutum en Italia se debe a una influencia celta "de reflujo", mientras que Eichberg parece creer que la expansión del scutum a la Transalpina es posterior a la adopción de la táctica y armamento manipulares en Roma.
}

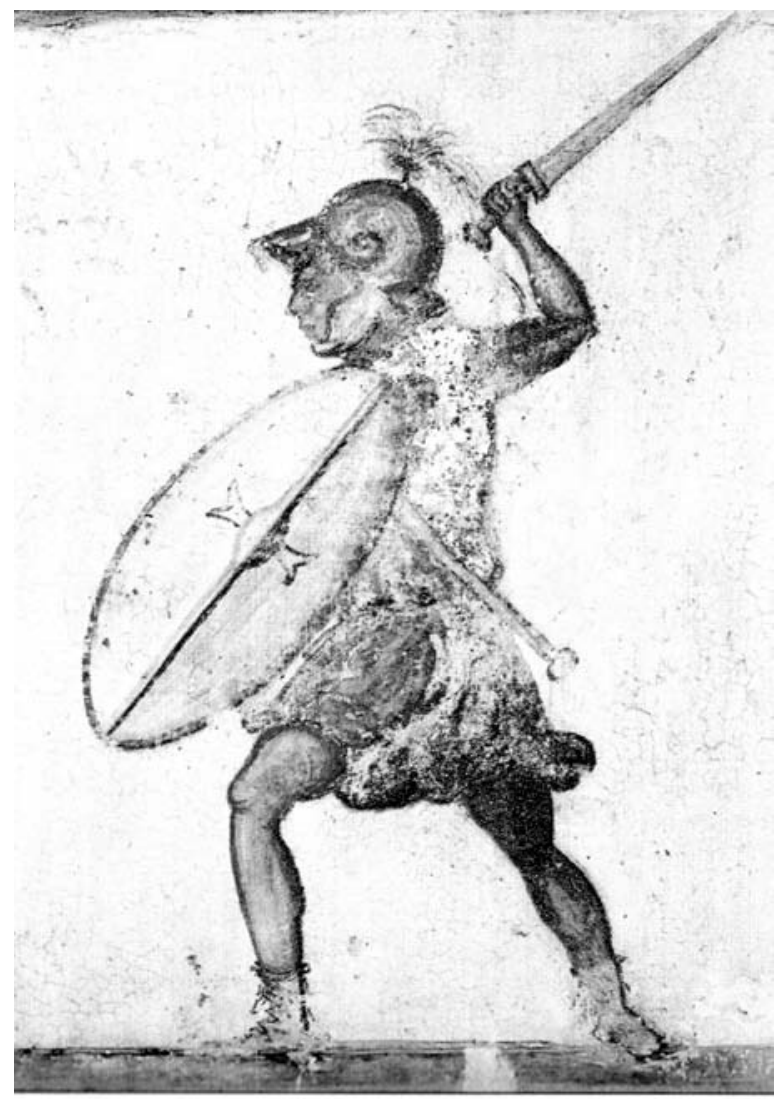

Fig. 4. Soldado helenístico con thureos o scutum. Estela de Dioskurides en Sidon. Museo de Estambul, Inv. 1490. Datadas entre fines del s. III-s. II a.C.

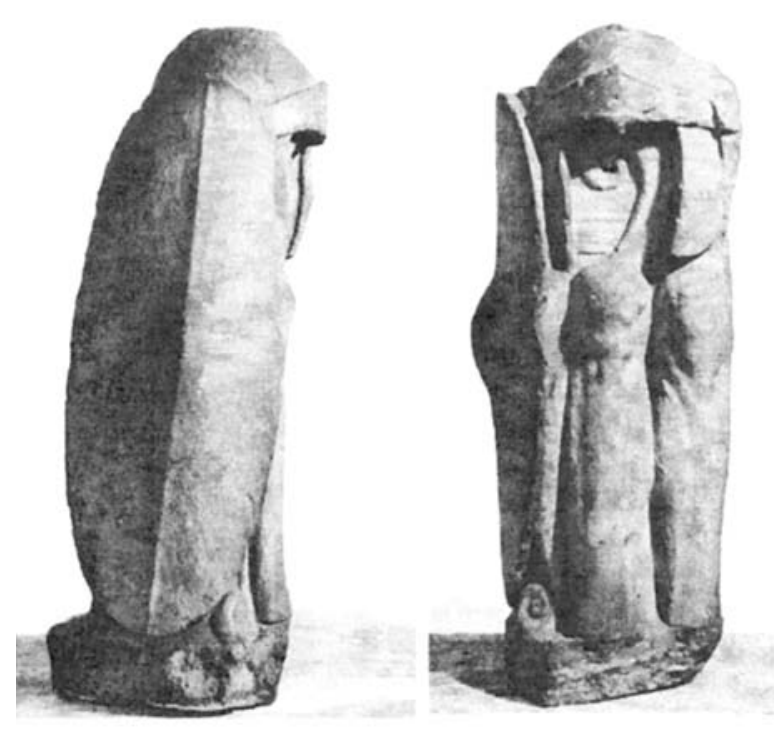

Fig. 5. Trofeo procedente de la llanura de Maraton. Mármol. Museo Británico Inv. 2142. Fecha discutida (s. II-I a.C.). El thureos podría ser también de tipo romano. 
o celta que helenística, ya que los tureoforoi como tales no parecen haber formado parte de los ejércitos cartagineses del s. III a.C., aunque sin duda un Aníbal debió reconocer de inmediato las ventajas de este tipo de escudo, igual que las habían reconocido los generales helenísticos y los mismos romanos. Desde luego en la Tercera Guerra Púnica, a mediados del s. II, el escudo oval era habitual en los arsenales cartagineses (Apiano, Afr. 93). Existen algunas estelas norteafricanas con escudos ovales de El Hofra, Cirta... (Berthier, Charlier, 1955: Lám. XVII.A; Fantar, 1993.II:95) (Figura 6), pero han sido variamente adscritas a mercenarios ibéricos (Connolly, 1981:150) o incluso a soldados romanos, aunque hoy se tiende a fecharlas en el s. II a.C. (Fantar, 1993:vol.II, 94). M. Fantar escribía en 1993 (p. 95-96): “C'est au cours des guerres romano-carthaginoises que le bouclier long ou ovale semble avoir fait son apparition... Mais si le bouclier ovale est adopté par le soldat punique, le boclier rond n'a pas été exclui du répertoire des sculpteurs... Quoi qui'il en soit, la présence du bouclier dans les armées puniques ne souffre pas l'ombre d'un doute. A partir de la fin du IVe siècle [el subrayado es nuestro], le bouclier long ou ovale vint supplanter ou s'ajouter au bouclier rond, attesté dans le monde punique depuis, au moins, le VIe ciècle avant J.-C." Nótese que aunque Fantar al principio no se atreve a precisar, acaba proponiendo una fecha que, de ser correcta, implica que si el escudo oval estaba generalizado ya en Cartago en la Primera Guerra Púnica, el mundo púnico podría haber sido perfectamente responsable de su introducción en Iberia meridional en la segunda mitad del s. III a.C. Sin embargo, lo cierto es que los datos firmes disponibles (estelas, referencias literarias) son posteriores, y por tanto la fecha de introducción del escudo oval en Cartago sigue siendo debatible. En consecuencia, no es fácil atribuir la introducción del escudo oval en Iberia a los cartagineses, ya que todo depende de su generalización en la propia Cartago. En cambio, sí es más que probable que su difusión masiva en el ejército de Aníbal (Polibio, 3,114; Livo 22, 46) sí se debiera a un impulso de los generales púnicos, y en particular Aníbal, necesitados de las ventajas que el escudo oval proporcionaba a la lucha en formación cerrada.

En consecuencia, lo primero que debemos afinar con la mayor precisión posible es el momento de aparición del escudo oval en Iberia a partir de los datos literarios, arqueológicos e iconográficos, para luego tratar de su generalización o al menos extensión.

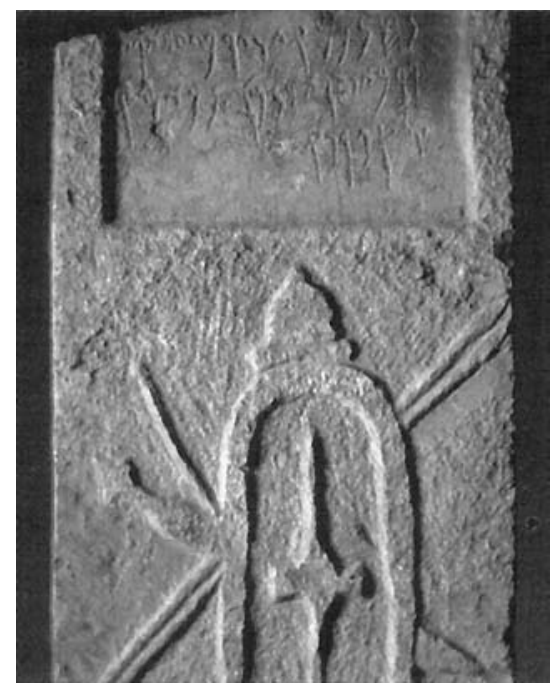

Fig. 6. Estela púnica del santuario de El Hofra con escudo oval, casco, dos jabalinas o lanzas y espada.

$$
\text { S. II a.C. }
$$

Las fuentes literarias constituyen una primera fuente de información a examinar sobre la aparición y empleo del escudo oval en Iberia. Independientemente de textos literarios sobre este arma en otras culturas, ${ }^{17}$ que han sido examinadas hasta la saciedad en los estudios genéricos ya ya citados sobre este arma y en los tratados sobre armas romanas, galas y helenísticas, hay unas pocas referencias literarias explícitas sobre Iberia que conviene recordar. De las fuentes más detalladas, Diodoro y Estrabón (en último lugar, con discusión, Quesada 2003b:88-90 y sobre todo la Tabla 1), sólo el primero $(5,33)$ indica que unos celtíberos portaban escudos redondos grandes, y otros thureos galos "ligeros" (de nuevo debemos entender ese "ligeros" por oposición al aspis griego que podía pesar hasta el doble). Desde el punto de vista histórico, las citas clave para la cuestión de la introducción del escudo oval entre los iberos, porque nos dan la primera fecha firme (216 a.C., batalla de Cannas) son los de Polibio $(3,114)$ y Livio $(22,46$, polibiánico) quienes insisten en la similitud de los escudos de galos e iberos (ambos largos) frente a las diferencias entre sus espadas. Esto en parte puede tener que ver con la forma en que Aníbal había armado a su infantería pesada, como veremos más adelante. Algo después, en 207 a.C., Magon se enfrenta a Silano en la Celtiberia, y dispone a sus mejores tropas, 4.000 scutati celtíberos, en primera línea, para poder resistir a los legionarios romanos armados de forma similar. Mucho más adelante en el tiempo se fechan las

17 E.g. Polibio, 2, 30; 6, 23; Livio 38, 21, 4; Diodoro, 5, 30; Estrabón, 4, 4,3; César, Bell. Gal. 1, 24, 3, etc. 
referencias a scutati sertorianos y cesarianos, que ahora no son relevantes para lo que nos ocupa (Quesada 1997a, 524 ss.;544).

Desde una perspectiva puramente arqueológica, en la Península Ibérica los hallazgos de umbos metálicos de escudo oval tienen una distribución muy claramente definida. Debemos distinguir tres grupos diferentes por su tipología y cronología: los bivalvos, los de aletas y los circulares. En total, conocemos en torno a treinta y cinco ejemplares (Quesada, 1997a:Apéndice IV), y no hay novedades sutanciales en cuanto a datos respecto a lo que recogimos en su momento (Quesda 1997a:538 ss.), aunque sí, como estamos viendo, cuestiones importantes de interpretación que entonces quedaban menos precisadas. Conviene comenzar reordenando la estructura tipológica que entonces presentábamos, comenzando por los umbos bivalvos, que entonces quedaban algo relegados.

Seguimos conociendo sólo cinco umbos bivalvos (Figura 7), todos de un tipo peculiar infrecuente en España al norte del Ebro. Proceden de una tumba inédita del Hinojal, en Arcos de la Frontera, Cádiz, asociado a una espada de La Tène I (Quesada 1997a, n. cat. 2156); tumbas 395 y 483 de Cigarralejo (nos. cat. 6291 y 6292); Sep. 4F-2 de Pozo Moro (n.cat. 6066) e Hipogeo H5 de Villaricos en Almería (n.cat. 2053). Los dos únicos con datación son los del Cigarralejo, en tumbas asociadas a fíbulas de La Tène I y datables dentro del s. IV a.C. sin poder precisar más. En cuanto a la Sepultura 4F-2 de Pozo Moro, cada vez estamos más convencidos de que hay dos ajuares mezclados, uno de la primera mitad del s. IV y otro superpuesto de finales del s. III o principios del II a.C., a no ser que admitamos una perduración de en torno a 150-200 años para el kantharos y el umbo de escudo, lo que tampoco es en modo alguno inaudito (Quesada 1997a:540-541; 562; ver también Alcalá-Zamora 2003:56 ss.). André Rapin ha reestudiado recientemente este tipo de umbos bivalvos con aletas en toda Europa (Rapin:2001); aceptamos su datación antigua para ellos, y por tanto consideramos que este grupo, que curiosamente se concentra hasta ahora en las regiones ibéricas al Sur del Júcar, se feche dentro del s. IV y probablemente asociado al fenómeno del mercenariado y sus centros de reclutamiento (Quesada 1994; Rapin, 2001). Sin embargo, en modo alguno podemos aceptar la fecha absoluta-

18 Quesada (1997a:538 ss.) para detalles tipológicos.

19 Sobre el escudo del castro de Alvarelhos, ver Soeiro (1980) y Quesada (2003b:97). mente forzada del s. V a.C. propuesta por Rapin para los ejemplares peninsulares (e.g. Rapin 2001:281, Fig. 5), ya que no hay datos que permitan sostener dicha fecha, y sí muchos en contra, en especial la cronología global del Cigarralejo, que no se remonta más allá de los comienzos del s. IV; sólo más adelante suaviza Rapin su propuesta, aceptando los fines del s. V- comienzos del s. IV para estos umbos ibéricos, fecha que sigue siendo quizá demasiado antigua en un cuarto de siglo.

Sin embargo, estos escudos ovales con umbo bivalvo no tuvieron continuidad ni aparentemente aceptación en el ámbito ibérico, y durante el resto del s. IV a.C. no conocemos ningún ejemplar al sur del Ebro.

En efecto, el segundo grupo de umbos de escudo oval es el formado por umbos de aletas - paralelas primero, abiertas desde fines del s. IIIa.C. $-{ }^{18}$ Estos sólo se documentan en Iberia al norte del Ebro (Quesada 1997a:538 y Fig. 312) asociadas a otros elementos de la panoplia céltica (espadas de La Tène con vaina metálica y suspensión por cinturón; moharras anchas) que son caractgerísticos del área catalana desde el s. IV a.C. en adelante (Quesada 1997a:624 y Fig. 343). A su vez, y de acuerdo a su contexto arqueológico, estos umbos se pueden dividir en dos subgrupos por su datación (Figura 7). El primero, hallado exclusivamente en el área catalana, está formado por los ejemplares de Cabrera del Mar, Turó dels dos Pins y probablemente en del Tossal de Les Tenalles, se fechan por asociaciones en ajuares funerarios a contextos de la segunda mitad del $\mathrm{s}$. III a.C., sin que sea posible precisar más; por tanto podrían estar asociados a la Segunda Guerra Púnica, pero también podrían ser anteriores.

El segundo subgrupo pertenece ya a época romana, y está formado entre otros por las piezas de La Azucarera, La Almoina de Valencia, y La Caridad de Caminreal, y quizá las de Le Corts de Ampurias y castro de Alvarelhos, ${ }^{19}$ se fecha ya hacia el 75 a.C., en época sertoriana, aunque hay algunas incertidumbres. ${ }^{20}$ Algunos de estos escudos, como los de La Almoina, pertenecieron claramente a legionarios romanos o tropas plenamente romanizadas, asociados como están a pila pesados e incluso catapultas (Ribera 1995; Vicente, Punter, Ezquerra 1997). Se aprecia también como abarca un área mayor, hacia el sur y el oeste.

20 Las piezas de La Azucarera podrían ser de fines del s. II a.C., al igual que las de Les Corts. 

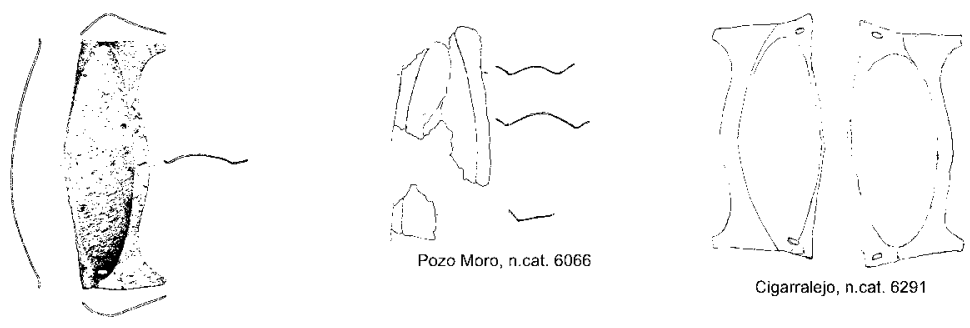

s. IV a.C.

Villaricos. N. cat. 2053
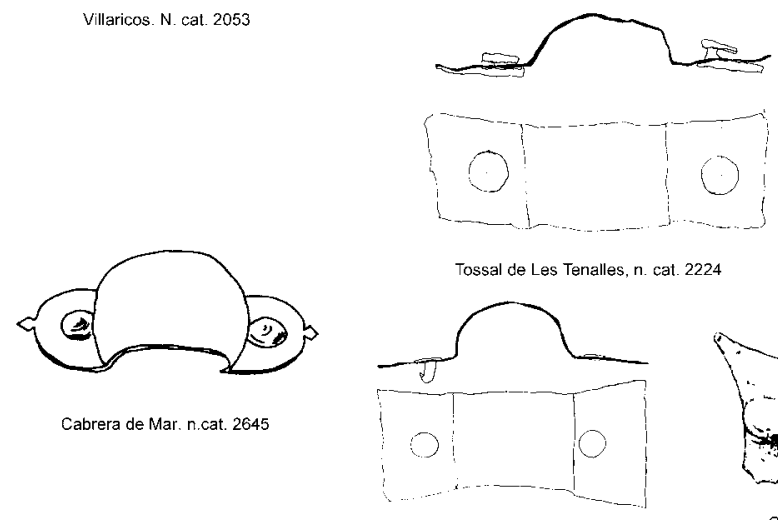

Cabrera de Mar. n.cat. 6318

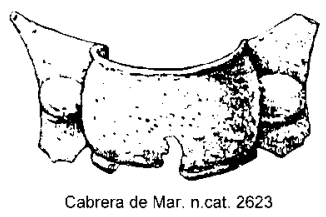

s. III a.C.
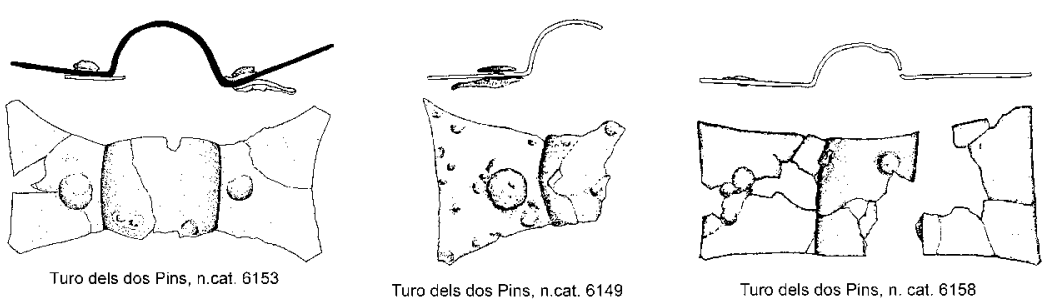

2/2 s. III a.C.
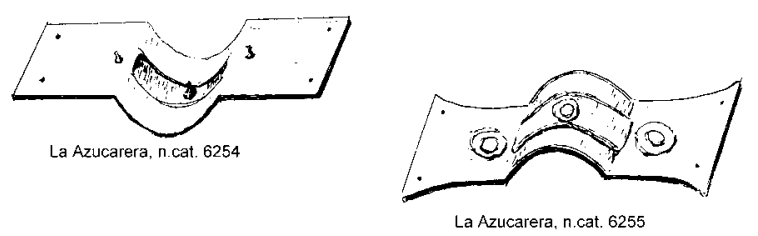

Fin. s. II a.C.

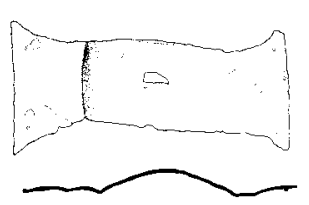

a Almoina, n.cat. 2689
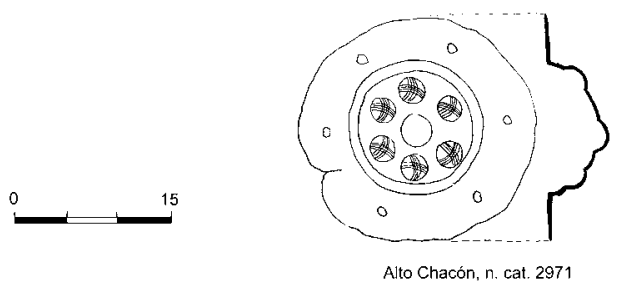
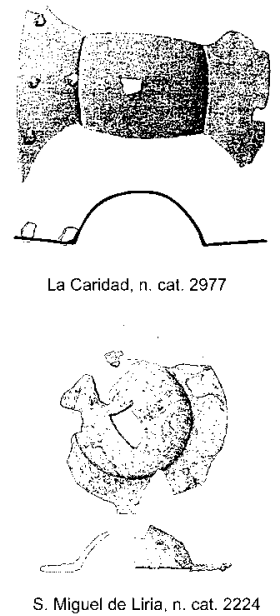

1/2 s. I a.C.

s. I a.C.

Fig. 7. Ejemplos de umbos de escudo oval en la Península Ibérica (los números de catálogo remiten a Quesada 1997a, Apéndice IV donde se hallarán detalles y bibliografía). 
El tercer grupo de umbos, posiblemente también de scutum, formado por piezas circulares grandes de en torno a $20 \mathrm{~cm}$. de diámetro (Figura 7) y en general fechable hacia mediados del s. I a.C., aunque con reservas pues puyede haber piezas algo anteriores, no requiere aquí de nuestra atención, pues no afecta a la cuestión del origen del tipo en Iberia (ver Quesada, 1997a:538 ss. para discusión).

Por tanto, la arqueología documenta la aparición aislada de escudos ovales con umbos bivalvos celtas en Andalucía y el Sureste durante el s. IV, que no parcen haberse generalizado. Luego, tras un hiato de quizá 150 años, reaparecen escudos con umbos de aletas de tipo también galo sólo en Cataluña. Versiones más avanzadas, con aletas trapezoidales, se asocian a contextos ya romanos de época sertoriana, pero sólo en el cuadrante nororiental de Hispania, sin que hasta ahora conozcamos umbos de este tipo al sur de Valentia. De esto podría deducirse que el mundo ibérico del Sureste no conoció el escudo oval tras una efímera aparición del tipo a principios del s. IV a.C., quizá en manos de mercenarios celtas, y que el scutum fue empleado sólo en el área catalana, fuertemente celtizada en su panoplia, desde

21 Para dicha cronología, ancla de lo que sigue, Bonet, Mata; 1982; Mata (1997:24-25); Bonet (1995:446-447). Esta autora es tajante: "Ningún yacimiento valenciano del siglo IV ha proporcionado decoraciones figuradas, lo que permite descartar de inmediato un comienzo de los estilos figurados en este siglo" (p. 447), que extiende a yacimientos como La Serreta, Puntal dels Llops, Cigarralejo, Oliva... e incluso S. Antonio de Calaceite o el Castelillo de Alloza en Teruel.

22 Para el vaso del Castellar de Oliva, recientemente reestudiado por C. Aranegui (2001-2002) también se acepta una fecha entre los siglos III y II a.C.

Más complejo es el caso de la cratera 'del desfile' del Cigarralejo (Cuadrado 1982, 1990), para el que se ha extendido en algunos sectores, contra la opinión de su excavador (Cuadrado, 1982:296; 1990:134) una datación de fines del s. IV a.C. (Conde, 1998:303), a nuestro juicio sin justificación estratigráfica o contextual (Blázquez, 2001-2002, donde se atribuye incorrectamente a un ajuar funerario; en realidad la pieza apareció en superficie) pero para el que, dada la forma del recipiente, cabría una datación anterior. Sin embargo incluso autores proclives a fechas antiguas para el origen de la decoración figurada aceptan una cronología del s. II a.C. (Olmos, 1992:82). V. Page, una de las mejores conocedoras de la cerámica de la zona, duda entre fines del s. IV por la forma del vaso y fines del III a.C. por la decoración, en lo que coincidimos plenamente (Page 1984:69). Ver también Blánquez (2003:195 ss.) quien acepta la fecha tardía, pero advierte sobre la mediados del s. III a.C., manteniéndose su empleo por la creciente presencia de tropas romanas a partir de principios del s. I a.C., posiblemente con tipos ya curvos y no planos.

Sin embargo, y como ya notara hace años $P$. Stary (1982:119), mientras que los objetos aparecen al norte del Ebro, las representaciones de escudos ovales se dan al sur, en territorio ibérico, y modifican sustancialmente el panorama. Probablemente las imágenes más antiguas de escudos ovales ibéricos son las representaciones sobre cerámica del estilo llamado de 'Liria', hoy fechado con fiabilidad en dicho yacimiento hacia fines del s. III o principios del s. II a.C., en plena Segunda Guerra Púnica y comienzos de la conquista romana, fecha extensible casi con seguridad a todas las muestras de este estilo pictórico vascular. $^{21}$ Por tanto, la cerámica indica una amplia extensión del escudo oval en el Sureste hacia mediados-fines del s. III a.C., y no hay ningún dato firme que permita una datación anterior. $^{22}$ De hecho, en la pintura vascular del Sureste y Levante en esta época el escudo oval pasa a predominar sobre el circular (Quesada, 1997a:521, Fig. 301). Una asociación con los acontecimientos en torno a la presencia bárquida

creciente aparición de cerámica con figuras humanas en contextos claros del s. IV en Andalucía.

También sin otro criterio que el estilístico se ha propuesto una fecha dentro del s. IV a.C. para el vaso cilíndrico de Archena (Pijoan, 1911-12; Olmos 1987:32, 41; Conde 1998:306) matizada luego a s. III a.C. (Olmos, 1992:138), pero a nuestro juicio una fecha similar a la de Liria sería una hipótesis mucho más simple y viable.

Carmen Aranegui defendió entre 1993 y 1997 la posibilidad de que el origen de la decoración figurada humana pudiera remontarse hasta c. 300 a.C. sobre la base incierta de ejemplos como el vaso del 'desfile' del Cigarralejo (Aranegui, 1993:555; 1997:195); sin embargo, en trabajos más recientes parece inclinarse por una fecha de c. 200 a.C. en adelante. Esta opinión choca con la de $\mathrm{T}$. Tortosa quien, siguiendo en esto a $\mathrm{R}$. Olmos, se plantea fechas algo más antiguas, dentro del s. IV a.C., para el comienzo de las representaciones figuradas (Tortosa, 1996:129 ss.) aunque matizando entre la existencia de vasos figurados ocasionales de encargo y la irrupción generalizada de estilos figurados (Tortosa 1996:139; también Conde, 1998:308). La irrupción de un nuevo estilo con figuras humanas no se derivaría en todo caso de un estilo precedente ni de una directa influencia helena (Aranegui, 2000:294-295, contra Olmos 1992:20; Conde 1998:309).

Los datos recientes con refrendo contextual o extratigráfico de zonas limítrofes tienden a confirmar las fechas de Bonet, con dataciones consistentemente posteriores a principios del s. II a.C. para la cerámica figurada 
y el comienzo de la Segunda Guerra Púnica se hace así casi inevitable (en esa línea, Bonet, Izquierdo, 2001:283) incluso si los primeros vasos con decoración figurada se remontaran casi cincuenta años, hasta c. 240 a.C. ${ }^{23}$

Ahora bien, ¿cómo son estos escudos?. Lo cierto es que en muchos casos apenas son una mancha oval rellena que no permite ninguna finesse tipológica, ${ }^{24}$ pero hay algunos casos (Figura 8) que nos permitirán avanzar ciertas consideraciones. En primer lugar, nada obliga a que el escudo oval tenga umbo metálico; de hecho, es muy frecuente que -salvo en el ejército romano los escudos ovales no tuvieran umbo metálico, sobre todo en las fases antiguas -ss. V-IV a.C.(Rapin, 2001:287-289; Randsborg, 1995:30 ss.); en cambio, la spina longitudinal, corta o larga, es un elemento característico del scutum o thureos en toda su área de difusión (Stary, 1981, Beil. 6). El escudo del Vaso de los Guerreros de Liria (Fig. 8.1) podría ser un escudo oval canónico: el

(Abad, Sanz Gamo, 1995:81). Lo mismo ocurre con estudios actuales de diversos yacimientos que, aún sin estratigrafías precisas, parecen ser consistentes con fechas posteriores a fines del s. III a.C. para la cerámica con figura humana (e.g. Izquierdo, 1995:102; Grau, 1996,1998-99).

Los trabajos de síntesis más recientes (Bonet, Izquierdo 2001) insisten en una datación de como mucho mediados/último cuarto del s. III a.C. para la irrupción de los estilos figurados con escenas en las que intervienen figuras humanas (Bonet, Izquierdo 2001:279).

23 Reproducimos aquí lo que escribíamos en 1997 y sigue siendo perfectamente válido: "La adscripción cultural de las figuras de guerrero que se reflejan en la cerámica del estilo de Liria depende en gran medida de la datación del mismo, que a su vez depende de la fecha de destrucción del yacimiento epónimo. Tradicionalmente se ha venido aceptando que tal destrucción coincidió con las guerras sertorianas, en torno al año 75 a. C. Si ello fuera cierto, el contexto del armamento empleado en las vasijas pintadas con escenas de guerra y otras de danza o desfile de carácter ritual sería ya romano, y los escudos serían scuta republicanos, como los citados de la Almoina de Valencia. A. García y Bellido, al estudiar las armas defensivas reflejadas en algunos de los vasos de Liria, llegó a la acertada conclusión de que la lorica squamata que algunos de ellos parecen reflejar, como los escudos y caligae, podrían no ser ibéricas, sino romanas, (García y Bellido, 1943:91 ss.). Por tanto, propuso que las escenas del Vaso de los Guerreros aludían a un momento de las guerras civiles de época de Octavio (4236 a.C.) o, menos probablemente, a la de Sertorio (c. 82-72 a.C.). De nuevo el contexto del armamento sería romano, ya se trate de un periodo u otro. Sin embargo, recientemente se ha demostrado con sólidos argumentos, basados en para- rombo podría ser una representación algo hipertrofiada de la spina y umbo, mientras que la banda horizontal podría indicar un umbo metálico de aletas rectangulares. Otros ejemplos de Liria (Figura 8, nos. 3, 8, 19) parece, con la línea vertical central, indicar de nuevo la spina, mientras que el ensanchamiento central del n. 19 también tiene un sentido estructural claro. Con sus lados paralelos y extremos redondeados estos escudos ovales podrían ser perfectamente itálicos, y menos probablemente helenísticos o celtas.

En cambio, la estructura de los escudos n. 4 y 44 (de Liria y Archena respectivamente) tienen un curiosa peculiaridad: se aprecia la mano del guerrero que los empuña, quien parece agarrar no la característica manilla corta horizontal de madera de casi todos los escudos ovales conocidos (cf. Quesada, 1997a:535-536) sino una estructura en forma de ' $x$ ' que podría corresponder a un sistema bien documentado etnográficamente en el Norte de Africa y otros lugares de

lelismos con el poblado cercano del Puntal dels Llops y en muchos otros motivos, que la destrucción del Tossal de San Miguel no debe datarse, pese a los hallazgos monetales, en el 786 a.C., sino a fines del s. III o principios del II a.C. (Bonet y Mata, 1982; Bonet, 1995). Así pues, el estilo de Liria debe datarse a fines del s. III a.C.; pero en todo caso, esto no altera la esencia del argumento de García y Bellido, aunque modificado: las figuras con scuta podrían ser tropas romanas republicanas, cartaginesas o, probablemente, soldados ibéricos al servicio de los cartagineses. En unos años turbulentos en que ejércitos extranjeros pasaban y repasaban a lo largo de la costa, ora hacia Sagunto, ora hacia Cartagena, no es de extrañar que los artesanos acabaran pintando soldados armados con extrañas corazas y grandes escudos que no supieron interpretar bien, porque eran de reciente introducción en la panoplia indígena para adaptarse a las nuevas y feroces formas de guerra que llevaban a cabo romanos y cartagineses sobre el suelo hispano. De lo dicho se deduce que es mucho más probable que los scuta de Liria, e incluso sus posibles imitaciones en mimbre con tirantes internos, deban atribuirse a tropas extranjeras o ibéricas al servicio de Roma o Cartago, que a la tradicional panoplia ibérica. La propia homogeneidad de la decoración de los escudos de todas las figuras de infantes del vaso 1 de Liria (Apéndice VI) es notable, y podría aludir a algún tipo de identificador de unidad, lo que sería más propio de un ejército muy organizado, no necesariamente extranjero." (Quesada 1997:543). Francisco Gracia ha reeditado recientemente esta idea de una base histórica para las escenas bélicas de los vasos de Liria (Gracia 2003:61).

24 Caso por ejemplo de Oliva, Aranegui 2001-02 con toda la bibliografía anterior, o del vaso del Cigarralejo, en último lugar Blázquez 2001-2002. 


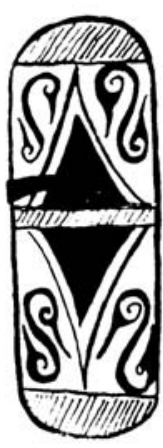

1

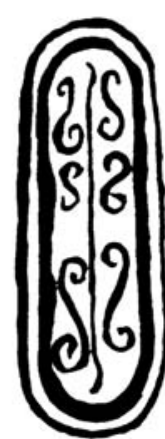

3

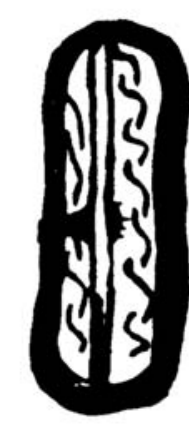

8

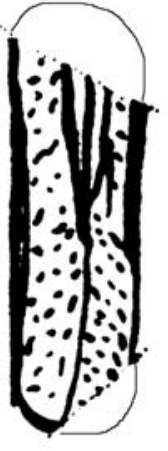

19

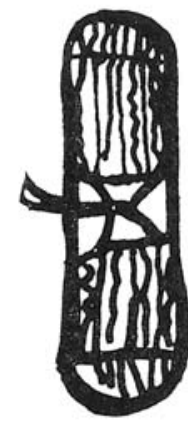

44

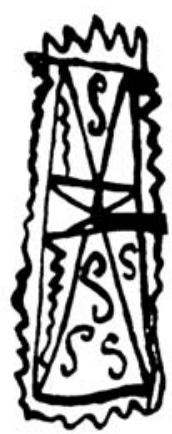

4

Fig. 8. Ejemplos de escudos ovales en cerámica ibérica en los que es posible discernir aspectos estructurales. Los números se refieren al Catálogo en Quesada (1997a:Apéndice 6). Todos corresponden a S. Miguel de Liria salvo el n. 44, de Archena.

correas tensas en dicha disposición (Kalus, 1977:44). Pero ello sería una peculiaridad única hasta donde sabemos e implicaría un escudo de estructura muy ligera, quizá de mimbre (como quizá el curioso patrón de relleno del n. 44 podría indicar), reforzado por tensores interiores (n. 4). De todos modos, en el contexto tardío del que estamos hablando resultaría una rareza este tipo de escudo, y quizá no debamos pedir demasiado al artista ibérico (Quesada 1997a:24-25) toda vez que, por ejemplo, el patrón que se emplea para el supuesto 'mimbre' sería el mismo utilizado para el cuello de un caballo o el cuerpo de un lobo en el mismo vaso (ver los dibujos excelentes de Olmos (1987). Por eso mismo es también discutible mantener como ya propusimos en su momento que algunos de estos escudo (Figura 8, n. 19) representan pieles sin curtir al exterior.

Las imágenes de escudos ovales en la plástica mayor presentan -en lo que a nuestra discusión nos afecta- menos dificultades que la pintura vascular. Claramente todas las representaciones son posteriores a mediados del s. III a.C. Sin duda los escudos mejor representados son los de Osuna, cuya spina, reborde metálico y umbo de aletas trapezoidales, además de forma oval plana, bien visible también en el relieve parisino (Rouillard 1997:32) lo clasifican mejor como de tipo galo o helenístico que como romano. Podría sin duda argumentarse que los escudos sean convexos, ya que es difícil representar en relieve la curvatura en forma de teja de un escudo. ${ }^{25}$ Puede desde luego contraargumentarse que los relieves

25 Aunque los romanos lo consiguieron plenamente en los tempranos relieves de Emilio Paulo en Delfos (prime- romanos tienen una calidad y dominio de la técnica ausentes en los iberos; pero entonces sale a colación el relieve iberorromano de legionarios de Estepa (Mus. Sevilla) en el que pese a una calidad técnica muy inferior a los relieves de Osuna la convexidad del escudo romano es clara (Figura 9), o el relieve de Minerva de la muralla de Tarraco (Noguera 2003:166-167). Desde el punto de vista cronológico, los relieves deben a nuestro juicio fecharse en el s. II a.C. mejor que a fines del III (Quesada 1997a:541; Leon, 1981:189; contra Noguera 2003:161, matizado en p. 190); pero incluso la fecha más antigua casa con la que hemos visto para la cerámica figurada: así pues el periodo entre el desembarco de Amilcar en 237 y el comienzo de la Guerra de Anibal en 219-218 a.C. sigue siendo el margen más antiguo de la horquilla.

Otras representaciones escultóricas de escudo oval nos llevan a un ámbito cronológico contemporáneo o ligeramente anterior, el de las estelas bajoaragonesas, concretamente a la de Caspe y Calaceite (Quesada 1997a:Fig. 250) y el pilar estela de Caspe (Beltrán Lloris 1996:182-183). Todas las representaciones incluyen spina, pero mientras que las estelas representan escudos completamente ovales, posiblemente de tipo plano, el escudo del pilar estela es de lados paralelos, más acorde con el modelo romano. En todo caso, el empleo de escudo oval era indistinto entre infantes y jinetes (Eichberg, 1987: 201-205). Por fin, el relieve de Estepa (Fig. 9b) (en último lugar, Noguera 2003:175-176 citando la principal bibliografía anterior) es sin duda de

ra mitad del s. II a.C.) y Domicio Ahenobarbo (s. I a.C.) (Connolly, 1981:132, 226; Robinson, 1975:166-167). 

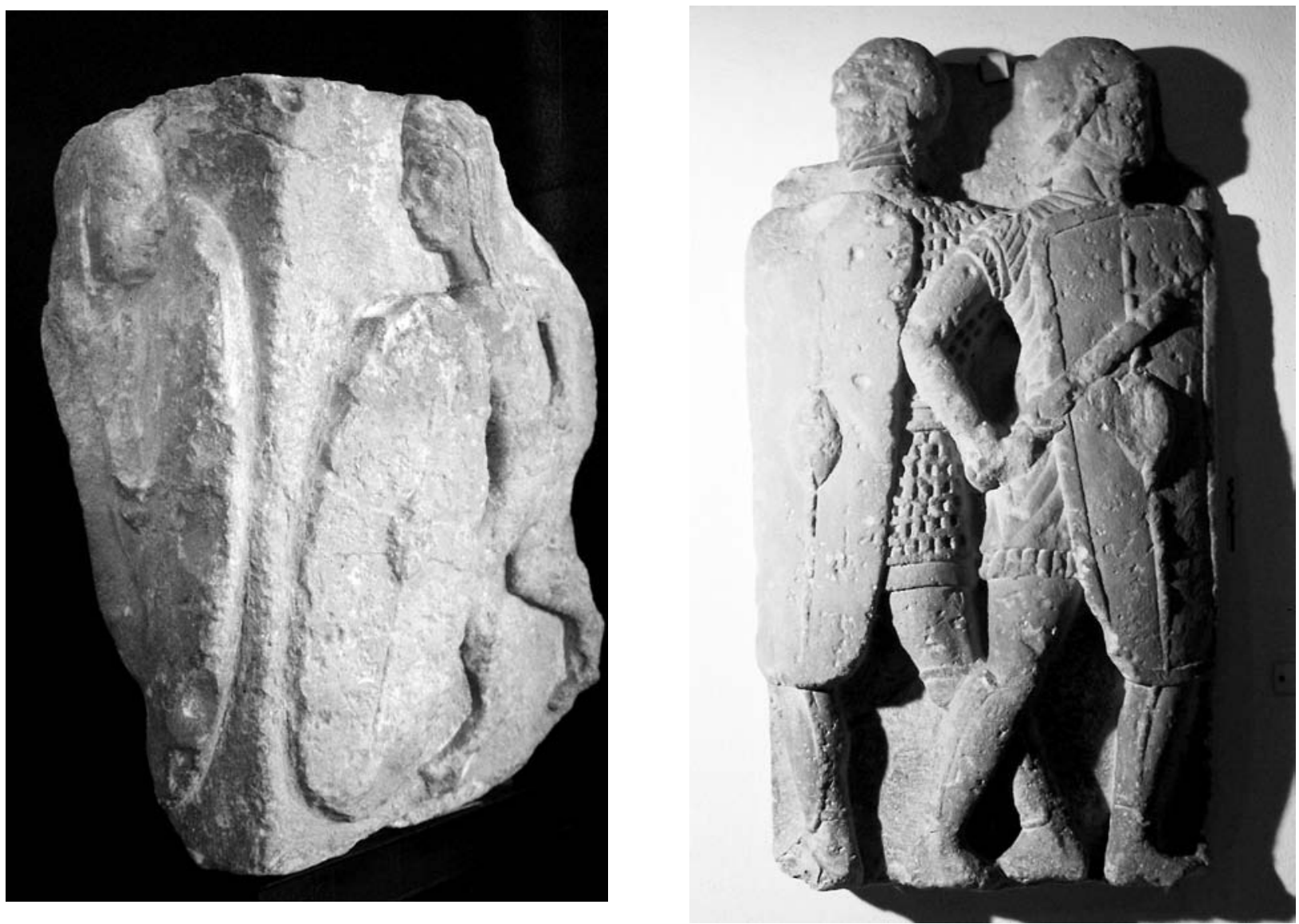

Fig. 9. Escudo plano de Osuna y escudo curvo de Estepa. Probablemente s. II y s. I a.C. respectivamente.

época sertoriana, cesariana o posterior, y por tanto claramente romano incluso si los representados son infantes scutati ibéricos. No es relevante pues para el origen del escudo oval en Iberia en manos ibéricas.

Es a nuestro juicio muy significativo que de entre miles de exvotos de bronce conocidos sólo uno del Collado de los Jardines, conservado en el Museo Cabré de Calaceite, lleve escudo oval (Cabré, 1939-40:Lam. XIX), y se trate claramente de un scutum curvo romano de lados curvos, en nada parecido a los de la cerámica, datable probablemente en época sertoriana o posterior (coincidimos en ello con Nicolini 1969:185). La patera de Tivissa, con una interesante iconografía de difícil interpretación ${ }^{26}$ presenta entre otras figuras a un jinete con lanza en alto y escudo oval de tipología inusitada en Iberia, con los dos extremos cortos acabados en pico en lugar de redondeados, y un esquema decorativo central en el que no se aprecia ni umbo ni spina. Obviamente, se trata de un tipo de escena en el que el orfebre conoce mejor los thureos ovales helenísticos e itálicos que los celtas (ver Eichberg, 1987). Los paralelos para esta forma de scutum aparecen en Italia y pinturas helenísticas de Asia menor desde el s. III a.C. (por ejemplo, Figura 4, en las ya citadas estelas de Sidon, $c f$. Sekunda, 1995). Así pues, pensamos que en este caso concreto el escudo oval de la patera tiene más que ver con la formación o paralelos empleados por el orfebre que con un escudo real que hubiera visto.

El famoso 'Flannery brooch', en el caso de que fuera finalmente una pieza auténtica ${ }^{27}$ (Figura 10) es tambien claramente plano, con umbo metálico de aletas rectangulares y orla, por lo que puede clasificarse como de tipo galo. Su asociación a un escudo de tipo Montefortino y a una espada recta de tipo La Tène, imitación hispana o gladius hispaniensis, y la tipología tardía de fíbula, asociada a las llamadas 'de escena venatoria', hace pensar en un jefe de alto rango, quizá mercenario, de la primera mitad del s. II a.C.
26 Marín Ceballos, (1983) con bibliografía anterior y Olmos en Chapa, (1986: 35 ss.; Pallarés 1991).

27 Discusión de Quesada y Megaw en Madrider
Mitteilungen, 44 (2004), p. 299. Ver de la Bandera, (1986) y Stead, Meeks, (1996). 


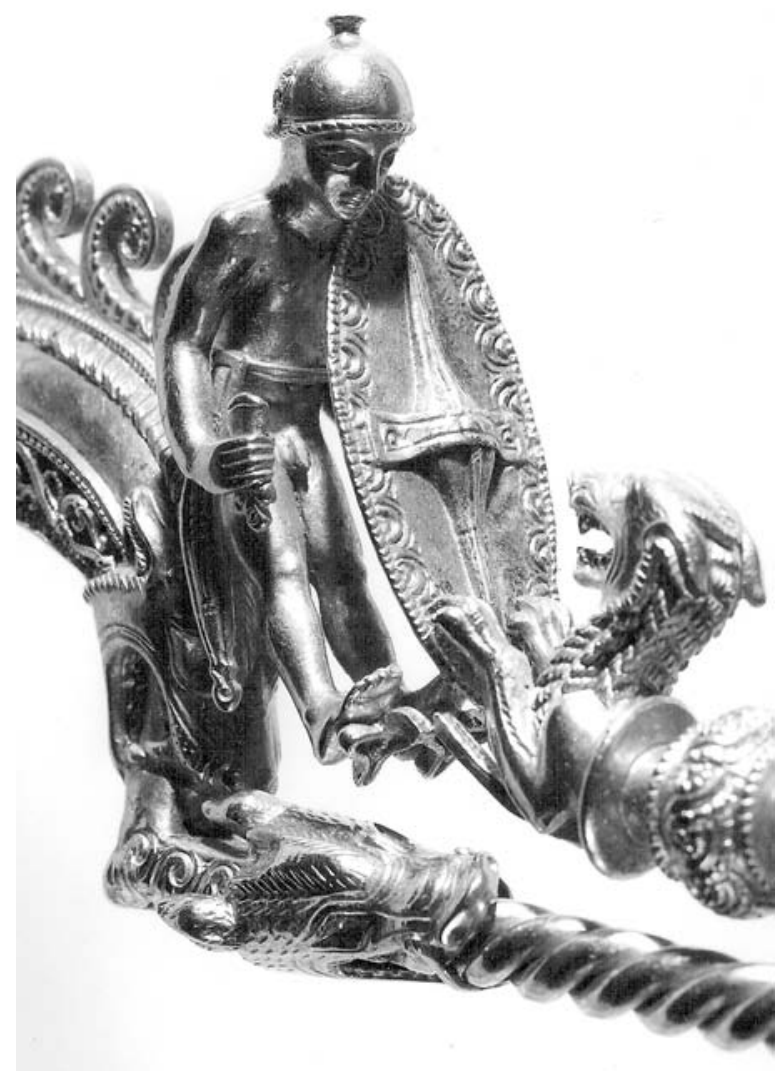

Fig. 10. Detalle del 'Flannery Brooch', gran fíbula aurea supuestamente hispana (Museo Británico).

En otro orden de cosas, parece realmente significativo que ni en los denarios emeritenses de Carisio, ni en las acuñaciones del Noroeste, ni en las monedas que recoge Guadán (1979) en su síntesis sobre armas en la moneda, aparece una sola vez el escudo oval (también Lorrio, 1995). En la enorme nómina de monedas con escudo de la Ulterior, y en la Citerior, el escudo oval brilla por su ausencia, y desde luego no porque el scutum no lo emplearan los jinetes (ya hemos visto por la cerámica de Levante y las estelas del Bajo Aragón que sí lo hacían). Sólo en una moneda de Ventipo (probablemente cerca de Santaella, en Córdoba), en una emisión datada por Villaronga a mediados del s. II a.C., aparece en el reverso un soldado con galea, signum y scutum (Villaronga, 1994:369, 1): sin duda se trata de un soldado romano, y el tipo iconográfico nada tiene que ver con la panoplia ibérica. Esto parece indicar que, por un lado, la tradición iconográfica que otorgaba al escudo circular una especial significación ya desde época prehistórica parece haber perdurado en época tardía (Quesada, García-Bellido, 1995:72); por otro que la

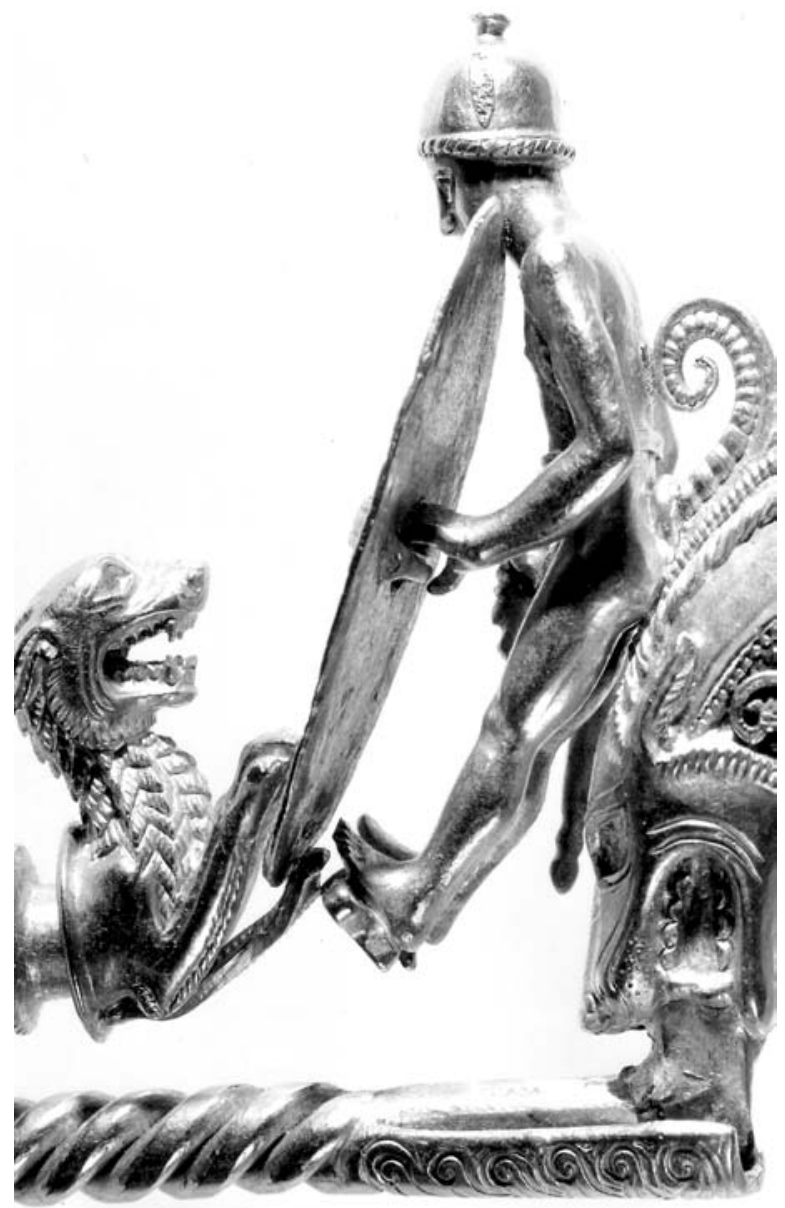

moneda no recoge exactamente la panoplia en uso entre los iberos o celtíberos de los siglos II-I a.C. (vid. infra para una ampliación de esta cuestión).

De todo lo que se ha dicho hasta ahora se puede sintetizar que el escudo oval era un arma hasta $c .330$ a.C. ajena al mundo peninsular, que empleaba para su infatnería 'de línega' el escudo circular de dos pies o más de diámetro (Quesada 1997a:528-531). Su penetración en la Península fue pues hasta cierto punto marginal en el tiempo y en el espacio; se introdujo desde la segunda mitad del s. III a.C. y en varios ámbitos diferentes. Por un lado, el scutum galo con gran umbo metálico aparece sólo en la zona catalana, quizá desde mediados del s. III a.C. donde se asocia a otro armamento típico de La Tène. Ya en el s. I a.C. el scutum que aparece en contextos sertorianos en Valencia, Teruel o La Rioja debe asociarse directamente a las legiones romanas (no parece probable que la catapulta de La Caridad de Teruel que se halló con los escudos y un casco Montefortino $^{28}$ perteneciera a civiles indígenas

28 Vicente, Punter, Ezquerra, 1997. 


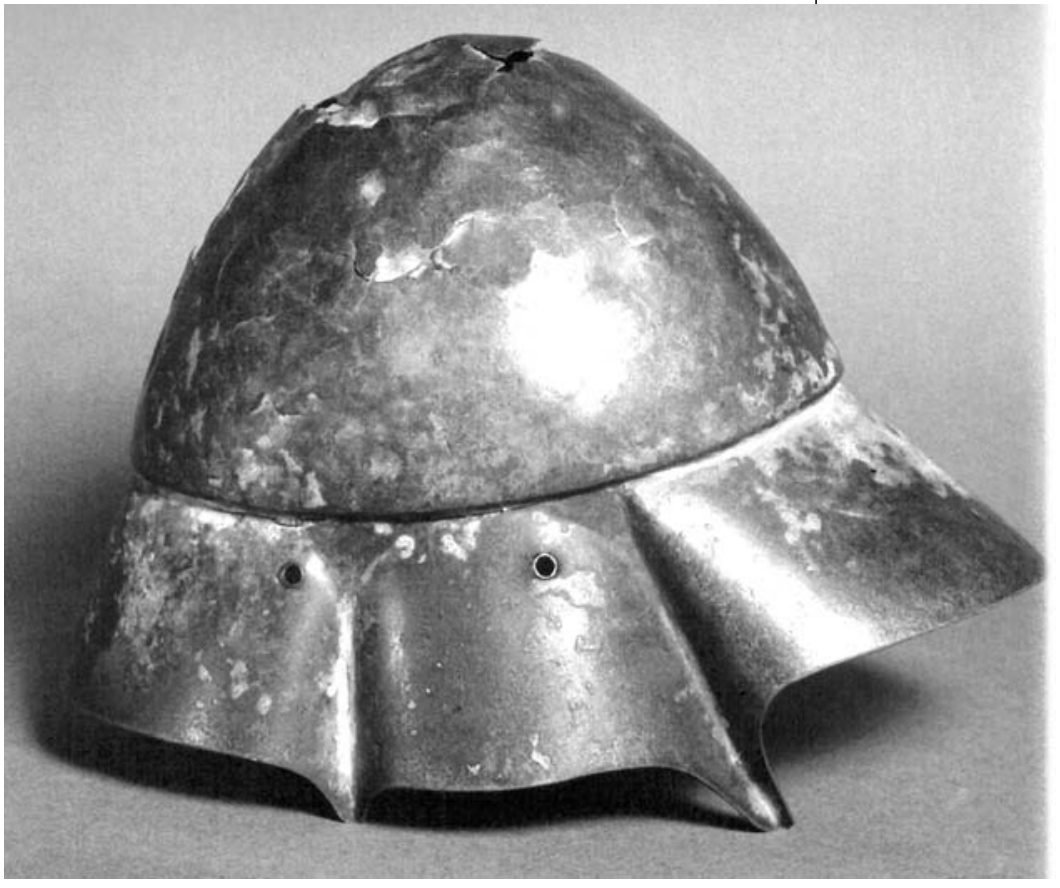

Fig. 11. Casco de caballería griego del tipo llamado 'beocio' recomendado ya por Jenofonte. No aparece en Iberia.

armados apresuradamente). Por otro lado, el escudo oval aparece representado desde fines del s. III a.C. (no hay todavía hallazgos de realia porque no existían umbos o manillas metálicos, lo que es hasta cierto punto normal) en esculturas y cerámicas ibéricas.

Ante el estado de cosas que hemos resumido, ya no es posible explicar las representaciones levantinas y meridionales como una expansión del armamento céltico septentrional, tal y como (ciertamente hace dos décadas) hacía Stary (1982:121); pero tampoco se puede aceptar la idea de Eichberg (1987:216) cuando piensa que la presencia de scuta en el Sureste se asocia a la presencia romana, ya que hemos probado la aparición de estos escudos décadas antes de la llegada de romanos. A nuestro modo de ver, sólo cabe asociar la aparición y extensión de este tipo de escudo oval en el Sureste a la presencia cartaginesa en Iberia, y en particular a la recluta masiva de tropas para el proyecto anibálico.

\section{INNOVACIONES EN LAS TÁCTICAS, TIPOS DE TROPA.}

Las innovaciones en armamento que hemos descrito no se deben lógicamente al azar o a la moda. Suponen por el contrario una alteración suficientemente significativa del armamento tradicional ibérico que debe explicarse en términos de variaciones en las tácticas, ya que en el mundo antiguo son casi siempre las alteraciones tácticas (a su vez causadas a menudo por cambios demográficos o de organización social) las que determinan los cambios en el armamento, y no al revés (por ejemplo, para el caso del aspis hoplita, Hanson 1991:63 ss.; en general, también Gracia 2003:35 nota 1 ).

A nuestro juicio, y dada la horquilla de fechas de adopción del escudo oval y de los cascos Montefortino, además de la extensión del gladius hispaniensis, hay que buscar las causas en la inmersión gradual pero acelerada de contingentes grandes de guerreros ibéricos, turdetanos y celtíberos en los ejércitos cartaginés primero (c. 237-c. 202 a.C.) y romano después (c. 218-c. 45 a.C.). La nueva situación, sin alterar en lo esencial las formas tradicionales de combate, introducía mayores peligros en un campo de batalla de mucha mayor intensidad de lo acostumbrado tradicionalmente, y durante periodos más prolongados. Por tanto, la mejora del armamento defensivo era especialmente acuciante.

Por otro lado, y dado que tanto cartagineses como romanos se hallaban crónicamente cortos cortos de infantería 'de línea' (esto es, que combatía en formación, independientemente de la pesadez de su armamento defensivo) durante los últimos años del s. III a.C., integraron no sólo contigentes especializados como los honderos baleares o unidades de caballería, sino masas de infantería empleada al modo de los peltastas o thureophoroi helenísticos, es decir, una infantería de uso doble, capaz tanto de combatir en línea, y así de enfrentarse incluso a la infantería pesada legionaria u hoplita-, como de luchar desplegada en guerrilla en terreno abrupto. Ese es el uso que más a menudo, y leyendo con mayor respeto a los comentaristas grecolatinos, se documenta en las fuentes literarias, como hemos estudiado ya detalladamente (Quesada, 1997a:657 ss.; 1997b, 2003), y como otros investigadores comienzan a aceptar (Gracia 2003:257 ss.; 306-307 en idéntica línea argumentativa) frente al anterior paradigma que, por razones más ideológicas que académicas, defendía las esencias de la 'guerrilla ibérica'.

En orografías difíciles, como la itálica o la hispana, estas tropas tenían una gran utilidad, y además aprovechaban las formas naturales de combate de los iberos desde al menos principios del s. IV a.C. En esta forma de combate es especial- 
mente útil el escudo oval o thureos de tipo helenístico o galo (más liviano que el scutum en forma de teja romano y no mucho más pesado que una caetra de $60 \mathrm{~cm}$., que protege peor el cuerpo en un combate en formación). Por ello, y a juzgar por la iconografía, el empleo del escudo oval comenzó a calar, a partir de las tropas reclutadas, aliadas o mercenarias, en todo el ámbito peninsular desde el fin del s. III, perdurando hasta las scutatae cohortes de época cesariana, ya a mediados del s. I a.C. Este empleo táctico de tropas es muy similar al de los thureophoroi helenísticos, que a su vez son herederos de experimentos con peltastas iniciados ya en la primera mitad del s. IV a.C. (en último lugar, Moreno 2002), y que, recordemos una vez más, constituyen una clase aparte intermedia entre la infantería pesada hoplita o falangita y los psiloi o infantes ligeros puros (a menudo confundidos con los peltastas) (Arriano, Táctica 3, 1-4; Eliano, Táctica K28). La adopción del casco de tipo de 'gorra de jockey', producido en Italia masivamente y, como se ha visto, adoptado en todo el Mediterráneo, responde también al mismo fenómeno: es un tipo de pieza que protege bien, es relativamente liviano y fácil de producir en comparación con otros tipos anteriores de raiz itálica o helénica, como los italocorintios, apulocorintios, italocalcídicos, etc.

Otra innovación importante a partir del s. III a.C., pero no necesariamente de raíz helenística vía Cartago, fue el desarrollo creciente de unidades de caballería, casi inexistentes antes (Quesada 1998; contra Gracia 2003:134 para quien su germen está hacia el 400 a.C.). Probablemente su aparición vino impulsada por las necesidades del los cartagineses, pero era factible porque como escribíamos en 1988 ya existía desde el s. IV a.C. una caballería celtibérica, estímulo que resulta mucho más probable y directo que el exclusivamente púnico en el desarrollo de la caballería ibérica.

La caballería ibérica no fue una caballería 'de línea' armada con lanza larga y diseñada para el choque, pese a que algunos reversos de monedas ibéricas pudiera parecer lo contrario (Quesada 1997a:420; Lorrio 1995 -celtíberos-). En efecto, según las fuentes literarias los jinetes ibéricos y celtíberos combatían con jabalinas o lanzas cor-

29 Cuya tradición se remonta a las monedas muy diferentes de jinete ligero desnudo o vestido con dos jabalinas y kausia o 'boina' macedonia de principios del s. $\mathrm{V}$ a.C. Sin embargo, el prototipo de las monedas centromediterráneas está sin duda en las monedas ya pos- tas e incluso desmontaban para luchar a pie (Quesada 1998:176-178 y Apéndice I para las fuentes; también Seco, de la Villa, 2003:132 ss.). La iconografía cerámica de San Miguel de Liria, mucho más precisa que la monetal, confirma esta idea, indicando incluso el amentum (Quesada, 1997a:414 ss. y Fig. 252). Aún así, sin duda hay ocasionales representaciones cerámicas, por ejemplo del Cabecico del Tesoro (Quesada 1997a:956, n.cat. 46) o de Archena (Quesada 1997a:955, n.cat. 44) en las que jinetes se enfrentan con infantes empuñando y no arrojando una lanza corta, pero en todo caso no es la larguísima lanza de la caballería pesada helenística (Manti 1983), que es la representada en las monedas ibéricas antes mencionadas, de inspiración helenística.

En efecto, las monedas ibéricas de jinete lancero pesado sufren una dependencia iconográfica directa helenística a partir de acuñaciones sicilianas (Arévalo, 2003:66 y Fig. 19, moneda de Hieron II de Siracusa, c. 274-216 a.C.; Domínguez Arranz, 1997:170 ss.), que a su vez probablemente derivan de monedas macedónicas de lanceros pesados (Almagro Gorbea, 1995:58 ss. y especialmente p. 60; 1995b; Picard 1986:68) ${ }^{29}$ aunque estas no parecen inspiración directa de las ibéricas.

Debemos recordar además, que las primeras acuñaciones ibéricas no son las de lanceros, sino las de jinetes a secas (Arevalo, 2003:67), que encajan con la tradición aristocrática ecuestre que se remonta a los caballeros armados como los de Porcuna, o inermes como los esculpidos como estelas funerarias de bulto redondo en la necrópolis albacetense de Los Villares, durante el s. V a.C. (Blánquez 1992). Consideramos que, aunque todas las monedas de jinete ibéricas responden a una tradición de prestigio ecuestre común, los prototipos debieron ser varios e independientes ${ }^{30}$ en momentos ligeramente diferentes, y que de las monedas de jinete inerme con palma de kese un artesano ibérico nunca pudo deducir el jinete pesado de tipo helenístico armado con casco y contus empuñado por bajo, que responde a un tipo muy concreto, en la tradición de los hetairoi macedónicos a caballo. A la inversa, el tipo de 'compañero' helenístico no tiene por qué ser origen de otras variantes, como el

teriores anónimas antiguas, y luego de Demetrios Poliorcetes (Picard, 1986:F68, Apdo. d).

30 Coincidimos en ello con Almagro Gorbea (1995b: 242). 


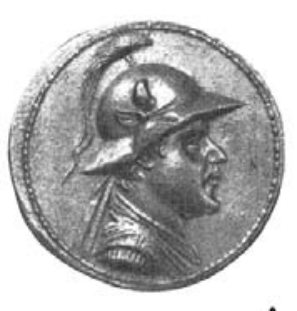

A

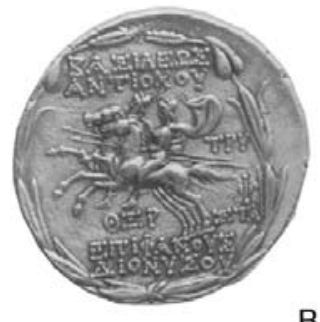

B

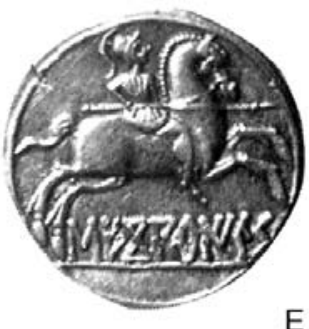

$E$

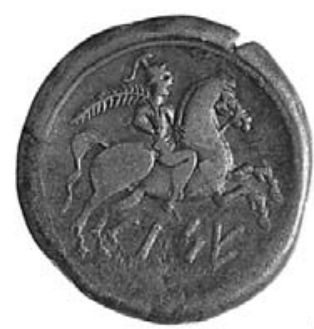

$\mathrm{F}$
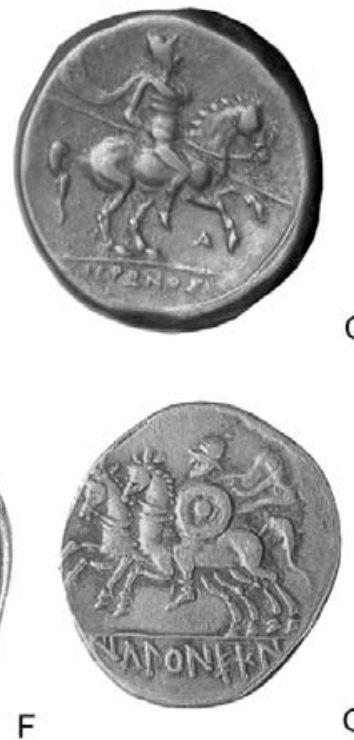

C

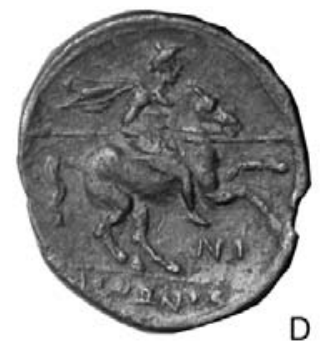

G

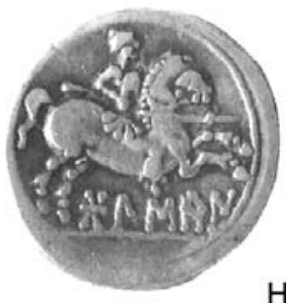

Fig. 12. La adaptación ibérica del casco beocio del jinete helenístico en monedas de jinete armado e inerme. A. Estátera tardohelenística de Eucratides I de Bactria (180-150 a.C.) con una versión tardía de casco beocio con cresta. B. Tetradracma de Antioco IV de Siria (145-142 a.C.). C-D. Bronces de Hieron II de Siracusa (fin s. III a.C.) con lancero con contus y casco beocio (en este caso sin penacho.(MAN de Madrid, nos. XXII-87-2-38 y XXII-87-2-39). E-H. Monedas de varias cecas peninsulares a lo largo del s. II a.C. (kelse, sekobirikes, ikalensken, bolskan) con diversos grados de adaptación al prototipo de casco beocio, desembocando en la sustitución por un tipo de 'gorra de jockey' que no se da en las modelas magnogrecas o sicilianas. Apreciese que no todas ellas son de lancero (bronce de kelse) (Piezas no a la misma escala).

jinete con palma o la variante de dos caballos con un jinete. ${ }^{31}$

A nuestro modo de ver, hay que explorar la posibilidad de que cuando los abridores de cuños ibéricos imitaron monedas siracusanas de Hieron II y otros tipos helenísticos, se encontraron con imágenes de pequeño tamaño de jinetes que llevaban un casco o tocado, que a veces podría ser la kausia macedonia, o un casco ático, pero que más a menudo era el casco beocio, típico de la caballería helenística pero completamente desconocido en Hispania (Figuras 11 y 12). Ahora bien, como estos artesanos ibéricos sí que conocían, por haberlos visto repetidamente en sus caminos y ciudades, los cascos de tipo Montefortino (vid. supra), tienden en su confusión a dibujar un tipo híbrido a caballo entre el beocio (con sus amplias cubrenuca y visera) y el Montefortino (sin visera, más bulboso y con el característico remate globular o cilíndrico ausente en el casco beocio). Los cuños más fieles se

31 Estas reflexiones se han beneficiado de amenas -y vivas- conversaciones con Alicia Arévalo, Paloma Otero y Carmen Marcos. Ni que decir tiene que los razonamientos y las conclusiones presentadas son únicamente responsabilidad del autor. acercan mucho a los prototipos helenísticos, y reproducen con cierta fidelidad el casco beocio; los que no contaron con prototipos directos, o copiaron de memoria, o partieron para abrir sus propios cuños no ya de monedas helenísticas, sino de piezas ibéricas, lo sustituyen por un tipo híbrido de beocio y etrusco itálico, inexistente en la realidad; o directamente lo cambian por un Montefortino (Figura 12). ${ }^{32}$

No es necesario en este proceso que las monedas ibéricas más antiguas sean las más fieles en sus detalles a las monedas griegas: una emisión relativamente tardía realizada a partir de un modelo ya añejo -quizá viejo de cincuenta añospero bien conservado, puede ser más fiel al prototipo helenístico que una emisión más antigua que no contó a la vista con dicho prototipo bien conservado. Además, conviene tener en cuenta que no sólo pudieron imitarse monedas siracusanas, sino también otros modelos iconográficos adecuados en forma y tamaño, como por ejem-

32 No nos parece que haya contaminación con el petaso o gorro blando de fieltro de ancha ala usado por los griegos para viajes (contra, Domínguez Arranz, 1997: 169). 
plo gemas helenísticas: pensamos por ejemplo en la impresión en positivo sobre barro de una probable gema o sello helenística -o helenístico romana- conservada en el Museo de Jaén (Figura 13), que presenta un jinete a la derecha cargando sobre un enemigo caído.

Una conclusión del proceso que proponemos es que no es factible considerar estas monedas ibéricas o celtibéricas ni como un todo unitario iconográficamente hablando, ni menos aún como una fuente fiel para el estudio del armamento ibérico. Más bien hay que verlas como muestra de las peculiaridades de los procesos de transmisión y adaptación iconográfica, en los que se mezclan probablemente tipos de armas copiados de prototipos ajenos (que nunca se usaron en Iberia), junto con tipos híbridos inexistentes producto de la (de)formación del abridor del cuño, y finalmente junto con otros existentes en la realidad de la Iberia del s. II a.C.

Sobre todo, este proceso es además a nuestro juicio un ejemplo interesante y muy engañososo de 'falso amigo' iconográfico. La introducción de una iconografía de tipo helenístico en la numismática ibérica (en este caso el tipo de jinete, en su variante de jinete pesado galeado armado con lanza larga empuñada a la altura de la cadera); no implica, pese a lo que una lectura directa y simplista pudiera hacernos creer, que también existiera en los ejércitos ibéricos ese tipo de jinete, armado con sarissa de caballería y empleando tácticas de caballeria pesada, que aparece representado en esa iconografía monetal. En realidad nos hallamos más bien ante dos ámbitos diferentes, el de la iconografía del jinete armado o inerme -perfectamente asumible y asumida por razones ideológicas de muy arcaico origen- y el de la realidad del campo de batalla -que estaba muy lejos de

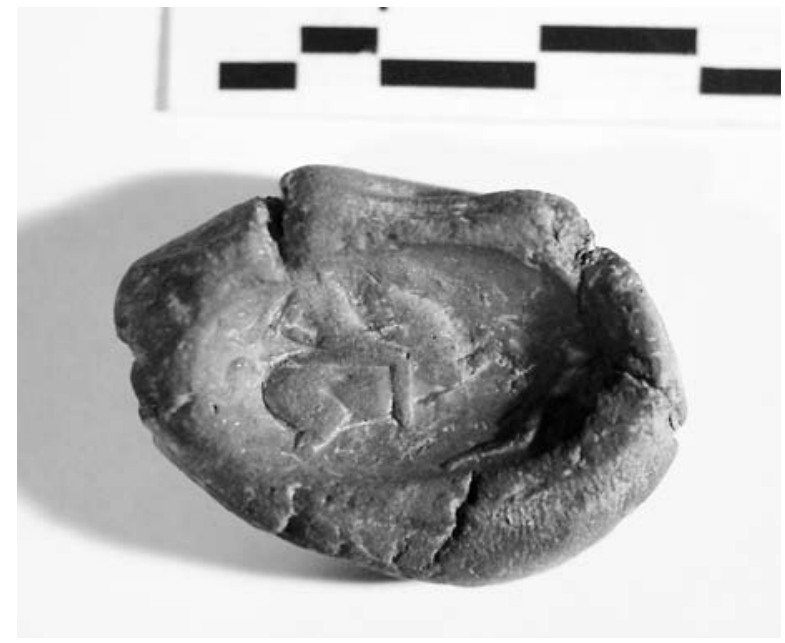

Fig. 13. Imagen -impresa sobre una pella de barro- de una gema o camafeo helenística o helenístico-romana. Museo de Jaén. N$^{\circ}$ Inv. 1793. poder asimilar una caballería pesada del tipo de los hetairoi macedónicos, cargando en formaciones de rombo o triángulo y armada con sarissa-.

\section{Campañas, mandos y logística}

En un nivel más general, que podríamos denominar 'operacional', nada indica que el panorama de razzias, saqueos y ataques estacionales, con ocasionales batallas campales y asaltos por sorpresa que se deduce de las fuentes literarias y la arqueología como característico de la guerra 'clásica' entre los pueblos ibéricos (Quesada 2003) no haya perdurado en lo esencial durante los siglos III-I a.C. No hay fuentes literarias, ni tampoco hasta el momento evidencia arqueológica, de guerra de asedio formal, ni empleo de máquinas de guerra entre los iberos (Moret, 1996:242 ss.; 2001; Quesada, 2001, 2003; contra Gracia 2000, 2001, 2003:225 ss.). Recordemos que siempre que las fuentes aluden a medios poliorcéticos sofisticados hay romanos o cartagineses por medio (véase el ejemplo del asalto a Orongis discutido desde puntos de vista diferentes por Moret 1996:256; 2001:140 vs. Quesada, 2001:149).

Por lo que se refiere a los mandos, los mercenarios de origen hispano como Merico, del que nos habla Tito Livio (Livio 25, 30; 26, 21, 1017) parecen haber sido profesionales, verdaderos condottieros, arrancados de sus raíces durante muchos años (ver también Polibio 1, 67), y encajan sin problemas dentro del mundo del mercenariado 'helenístico', pero no dentro del desarrollo interno de la Cultura Ibérica. Tras años o décadas fuera de su tierra, estos jefes mercenarios profesionales poco o nada aportaron al desarrollo de sus lugares de origen, y parecen haberse quedado en Sicilia o Italia.

Pero en Iberia propiamente dicha las cosas parecen bien distintas: los jefes que mandan contingentes ibéricos, sean de meridionales como Culchas (Livio 28,13; 33,21), ilergetes como Indíbil y Mandonio (Livio 29, 3), levantinos como Edecon o incluso celtíberos como Allucio (Livio 26, 50, 14) son aristócratas cuya autoridad deriva de su linaje (regiae nobilitatis, dirá Livio de Indíbil), en la que el matrimonio dinástico, como aprovecharían Asdrúbal o Aníbal, es costumbre (Diodoro 25,12; Livio 24,41,7). Estos líderes vendrán rodeados de una clientela fiel sobre todo al linaje, y nada indica que sean líderes militares básicamente carismáticos, aunque por supuesto el éxito o la capacidad militar ayudaría a elevar su reputación y autoridad (ver Coll, Garcés 1998). La referencia a Istolacio, strategos céltico que conduce tropas mercenarias al servicio de 
los turdetanos (Diodoro 25,10,1) no puede tomarse directamente como la de un condottiero de tipo helenístico, ya que nada sabemos sobre su status y la naturaleza de su autoridad en su patria de origen.

Lo poquísimo que sabemos sobre aspectos como paga, aprovisionamiento y en general la logística entre los iberos (Quesada 2003) nos indica que no había guarniciones permanentes de mercenarios en lugares estratégicos (pese a las propuestas en contrario que se han hecho sobre hipotéticos mercenarios celtíberos controlando la minería de la plata de Sierra Morena, Quesada 1997a:107, 631; contra García Gelabert, Blázquez, 1987-88; Blázquez, García Gelabert 1992; discusión detallada en Quesada 1999), ni asentamientos de clerucos o similares, ni provisión por parte de unos fantasmales 'estados' ibéricos para las necesidades de la guerra. Antes bien, lo que sí sabemos es que las lealtades en la guerra se concebían en clave personal, no estatal (Livio 29, 3; ver Quesada 1997:67), que el saqueo de rebaños y la destrucción de cosechas eran las actividades bélicas habituales (Quesada, 2003 passim y espec.

\begin{tabular}{|c|c|c|c|c|c|}
\hline NIVEL & RASGOS CARACTERÍSTICOS & NO & $<?$ & $?>$ & SI \\
\hline \multirow{4}{*}{ ARMAMENTO } & -Tendencia estandarización y fabricación masiva & & & & \\
\hline & -Resurgir de la armadura metálica & & & casco & \\
\hline & -Pica en infantería y caballería & & & & \\
\hline & -Extensión del escudo oval & & & & \\
\hline \multirow{8}{*}{ TIPOS DE TROPA } & -Variedad y especialización. & & & & \\
\hline & -Profesionalización y mercenariado & & & & \\
\hline & -Importancia de la caballería pesada & & & & \\
\hline & -Falange falangita y hoplita & & & & \\
\hline & -Infantería de uso mixto & & & & \\
\hline & -Importancia de la inf. lig. especialista mercenaria & & & & \\
\hline & -Armas exóticas (elefantes, artillería) & & & & \\
\hline & -Complejidad étnica de los ejércitos & & & & \\
\hline \multirow{4}{*}{ TÁCTICA } & -Coordinación interarmas & & & & \\
\hline & -Operaciones todo tiempo & & & & \\
\hline & -Tretas complejas, reservas... & & & & \\
\hline & -Asedios complejos & & & & \\
\hline \multirow{2}{*}{ MANDOS } & -Profesionalización en los mandos & & & & \\
\hline & -Liderazgo por carisma militar & & & & \\
\hline \multirow{4}{*}{ LOGÍSTICA } & -Compleja, en parte provista por el Estado & & & & \\
\hline & -Complejidad pagos a contingentes mercenarios & & & & \\
\hline & -Guarniciones permanentes con mercenarios & & & & \\
\hline & -Asentamientos militares tipo clerucos & & & & \\
\hline
\end{tabular}

Fig. 14. Posible aplicación al mundo ibérico de rasgos militares típicos de época helenística. "< ?” indica escasa probabilidad; "? >” indica cierta probabilidad. 
nota 12 ; ver por ejemplo Livio $21,61,6$; $28,24,4$; 28,32,9; 28, 33,2; 34,20,2; 34,21,1). Todos ellos son rasgos bastante arcaicos, comparables a los típicos de los siglos VI-V y quizá IV a.C. en la mayoría de los puntos del Mediterráneo central y oriental, pero ya desbordados en estas regiones en época helenística.

En este sentido, parece que a medida que avanza el tiempo, el décalage entre las innovaciones militares del mundo griego, itálico o púnico, y el ibérico, realtivamente reducido en el s. VI a.C., fue creciendo en lugar de cerrarse, hasta el punto de que a fines del s. III a.C. la distancia entre un ejército griego o púnico y uno ibérico era mucho mayor, en términos organizativos, tácticos y armamentísticos, de lo que había sido en los siglos anteriores. Para poner al día la buena materia prima que eran los guerreros peninsulares se hizo conveniente actualizar el armamento defensivo.

En síntesis, y como pretende reflejar la Figura 14 -con todas las cautelas propias de las incertidumbres del caso y la rigidez de la esquematización-, pocos de los rasgos que en su conjunto cartacterizan a la guerra helenística encuentran acomodo en los datos disponibles para el mundo ibérico, y todos ellos se refieren a los niveles más 'mecánicos' (armamento y táctica), sin afectar a la fábrica social y a las mentalidades: su penetración se debe a los contactos con el ejército púnico y romano, y a su implicación más o menos forzada en las Gueras Púnicas y luego en las Guerras Civiles romanas.

Los ejércitos ibéricos en sí mismos nunca se 'helenistizaron' salvo en la adopción de algunas armas y la potenciación de una infantería de uso dual como argumento táctico básico, y en esto no hacían sino seguir una tendencia ancestral propia de todas las regiones de orografía difícil del Mediterráneo.

\section{EN CONCLUSIÓN}

Que la Cultura Ibérica no se configuró en forma de estados helenísticos es una obviedad que a nadie se le oculta. Pero el grado y forma en que influencias, más o menos sutiles, en campos como el concepto de poder, la iconografía de la autoridad, la arquitectura representativa, la vajilla argéntea de lujo, o la milicia, pudieron irse impregnando de rasgos 'helenistizantes' entre el s.

33 Esto no implica que necesariamente adoptemos la postura de una introducción de la moneda celtibérica del jinete antes de la conquista romana, asociada en cambio a la demanda de las aristocracias ecuestres indígenas; o a
III y el I a.C. es cosa bien distinta y más difícil de matizar, por más que esa matización sea imprescindible si hemos de comprender 'lo ibérico' en su contexto. En la orfebrería, en la arquitectura, incluso en la milicia, hay abundantes indicios pero sólo indicios- que apuntan -y sólo apuntanen esa dirección. Iberia en los siglos III-II a.C., como en las centurias anteriores, estaba alejada de los principales centros culturales, políticos, económicos y militares del ecúmeno; pero no estaba herméticamente aislada. Mucho llegó al lejano Occidente, y no sólo en forma de vasos cerámicos de barniz negro; por ejemplo, los datos de la numismática muestran que la imagen helenística del poder, transmitida a través tanto de mediación púnica, como magnogreca y romana, caló hasta cierto punto en la Citerior en el s. II a.C., superponiéndose a la evolución interna de las aristocracias ciudadanas, especialmente en la Celtiberia (Almagro Gorbea, 1995, 1995b, 1996:125 ss.) ${ }^{33}$.

Ahora bien ¿hasta qué punto fue intensa y significativa esta influencia de corte helenístico en la estructura militar ibérica?. Nunca podremos saber qué hubiera ocurrido si Iberia hubiera seguido una evolución local propia, en relación con el resto del Mediterráneo pero libre de su inmersión en la "Guerra Mundial" que fue la Segunda Guerra Púnica y la consiguiente conquista romana. Es evidente que el desarrollo 'natural' del mundo ibérico se vió primero reorientado, y bruscamente cortado inmediatamente después. Pero sí podemos realizar una aproximación a lo que realmente ocurrió: y en síntesis es que en Iberia no se produjo una influencia sustancial de las innovaciones militares helenísiticas, más allá de lo epidérmico.

Ciertos tipos nuevos de armas -el casco de bronce y el escudo oval- hallaron bastante aceptación desde mediados del s. III a.C. en adelante, dado que ofrecían mejor protección, sobre todo en los casos en que contingentes peninsulares se vieron envueltos, más o menos voluntariamente, como súbditos, aliados o voluntarios en las guerras de Cartago y Roma. Con todo, ni cascos broncíneos ni escudos ovales ni espadas rectas desplazaron completamente la panoplia tradicional, y de hecho quizá fueran minoritarios hasta el s. I a.C, salvo el escudo oval.

Dada la escasez crónica de infantería que ambos bandos -cartaginés y romano- sufrieron

un momento asociado a la organización administrativa y fiscal republicana, tema todavía polémico en el que ahora no entramos (Almagro Gorbea, 1995b; García-Bellido 1993). 
durante los últimos años del s. III a.C., tendieron a reclutar no sólo contigentes especializados como los honderos baleares o unidades de caballería, sino grandes masas de infantería de uso doble. Esta forma de combate, para la que es especialmente útil el escudo oval o thureos de tipo helenístico o galo, parece haber calado en la generalidad del mundo indígena desde fines del s. III a.C., y haber perdurado hasta las scutatae cohortes de época cesariana, ya a mediados del s. I a.C.

Junto con el desarrollo de estos thureophoroi ibéricos la otra innovación importante es el desarrollo creciente de unidades de caballería, sin duda impulsada por la presión cartaginesa, pero que tampoco cabe considerar como una innovación propiamente helenística, sino de influencia celtibérica, aunque potenciada por las necesidades de los cartagineses y romanos.

Sin embargo, más allá de estas dos innovaciones tácticas que sin duda deben mucho a la influencia helenística, vía Cartago primero, y también via Roma inmediatamente después, no parece que la 'helenistización', si se nos admite el neologismo, profundizara mucho más en la estructura militar ibérica. Los rasgos tácticos más evolucionados (uso de falange de falangitas con pica, caballería pesada orientada al choque) están ausentes, así como los referidos a los aspectos más elevados del arte militar: ni la artillería o la guerra de asedio, ni las formas características del mando helenístico - condottieri profesionales y jefes militares carismáticos sin necesidad de autoridad por linaje-, ni la logística o la economía de la guerra parecen haber progresado más allá de los niveles alcanzados a principios del s. IV a.C., de rasgos relativamente 'arcaicos'.

En última instancia, pues, surge inevitable la impresión de que si durante las primeras décadas del s. IV a.C. el mundo ibérico había llegado a practicar unas formas de guerra no muy distantes de las practicadas en el mundo griego o romano no mucho antes, durante la segunda mitad de la centuria precedente (milicias ciudadanas amateurs y/o fuerzas clientelares, combate de infantería de línea en una agrupación cerrada más o menos estructurada, papel limitado de las tropas ligeras y jinetes), al llegar el final del s. III a.C. el décalage o desfase temporal entre el rápido desarrollo generado en el mundo helenístico y el comparativamente conservador 'lejano oeste' ibérico creció en lugar de reducirse. No hay en esto 'culpables' ni valoraciones: Iberia no se quedó atrás, simplemente no sufrió las convulsiones y mutaciones que caracterizaron el mundo de la milicia en el Mediterráneo central y oriental desde época de Alejandro Magno.

\section{Bibliografía}

Abad Casal, L.; Sanz Gamo, R. (1995) "La cerámica ibérica con decoración figurada de la provincia de Albacete. Iconografía y territorialidad". Hom. A M. Gil-Mascarell. Saguntum 29, 73-84.

Alcalá-Zamora Díaz-Berrio, L. (2003) La necrópolis de Pozo Moro (Chinchilla, Albacete). Tesis Doctoral Inédita, UCM. Madrid.

Almagro Gorbea, M. (1990) "L'Hellenisme dans la Culture Ibèrique". XIII International Congress of Classical Archaeology, Berlin. Mainz, 113-127.

Almagro Gorbea, M. (1995) "Iconografía numismática hispánica: jinete y cabeza varonil”. La moneda hispánica. Ciudad y territorio. Anejos AEspA XIV, págs, 5364. Madrid.

Almagro Gorbea, M. (1995b) "La moneda hispánica con jinete y cabeza varonil: ¿tradición indígena o creación romana?". Zephyrus 48, 235-266.

Almagro Gorbea, M. (1996) Ideología y poder en Tartessos y el mundo ibérico. Discurso de ingreso en la Real Academia de la Historia. Madrid,

Anderson, J.K. (1970) Military theory and Practice in the Age of Xenophon. Berkeley\&Los Angeles.

Aranegui Gasco, C. (1993) "La cerámica ibérica ante la Romanización”. Hom. A Miquel Tarradell, 553-558.

Aranegui Gasco, C. (1997) "Scènes de la cité ibérique. Les céramiques d'Edeta”. Dialogues d'Histoire Ancienne 23/1, 195-220.

ARAnegui Gasco, C. (2000) "Mostrarse en imágenes. Un recorrido a través de las decoraciones de la cerámica ibérica". Scripta in honorem Enrique A. Llobregat Conesa, vol. I. Alicante, 293-305.

Aranegui Gasco, C. (2001-2002) "A propósito del vaso de Los Guerreros del Castellar de Oliva”. Studia E. Cuadrado, AnMurcia 16-17, 229-238.

Arévalo González, A. (2003) "La moneda hispánica del jinete ibérico: estado de la cuestión". F. Quesada, M. Zamora (eds.) El caballo en la antigua Iberia, 63-74. Madrid.

Balil Illana, A. (1989) "De la escultura romano-ibérica a la escultura romana-republicana”. En Estudios sobre Urso. Colonia Iulia Genetiva. Sevilla, 223-231.

BAndera, M.L. de la (1986) "Posible fíbula ibérica con escena venatoria". AespA 59, 207-210.

Barcelo, P. (2000) Aníbal de Cartago. Madrid.

Beltrán Lloris, M. (1996) Los iberos en Aragon. Zaragoza.

Berthier, A.; Charlier, R. (1995) Le sanctuaire punique d'El Hofra à Constantine. Paris. 
BLÁNQUEZ PÉREZ, J. (1992) “Nuevas consideraciones en torno a la escultura ibérica”. CuPAUAM 19, 121144.

BlÁNQuez, J. (2003) “Conclusiones”, En J. Blánquez (ed.) Cerámicas orientalizantes del Museo de Cabra. Cabra, 187-203.

BlÁnquez Martínez, J.M. (2001-2002) "El vaso de los guerreros de El Cigarralejo (Mula, Murcia)”. Studia E. Cuadrado, AnMurcia 16-17, 171-176.

Blánquez Martínez, J.M.; García-Gelabert, M.P. (1992) "Relaciones entre la Meseta y Oretania". M. Almagro, G. Ruiz Zapatero (eds.) Paleoetnología de la Península Ibérica, 45-56. Madrid.

LE BoHec, Y. (1996) Histoire militaire des guerres puniques. Paris.

Bonet Rosado, H.; Mata Parreño, C. (1982) "Nuevas aportaciones a la cronología final de Tossal de Sant Miguel (Liria, Valencia)". Saguntum 17, 7783.

Bonet Rosado, H. (1995) El Tossal de Sant Miquel de Llíria. La antigua Edeta y su territorio. Valencia.

Bonet Rosado, H.; IzQuierdo Peraile, I. (2001) "Vajilla ibérica y vasos singulares del área valenciana entre los siglos III y I a.C.”. APL 24, 273-313.

BRIQUeL, D. (1986) "La tradition sur l'emprunt d'armes samnites par Rome". J.P. Adam y A. Rouveret (eds.) Guerre et societés en Italie au Ve et IVe siècles avant J.C. Les indices fournis par l'armement et les techniques de combat.Table Ronde, Paris 1984, 65-89. Paris.

BRIzZI, G. (1995) "L'armée et la guerre". V. Krings (ed.) La civilisation phènicienne et punique, 303-315. Leiden.

Brunaux, J.L.; Rapin, A. (1988) Gournay II. Boucliers et lances, dépôts et trophées. Revue Archeologique de Picardie. Paris.

Cabre aguilo, J. (1939-40) "La caetra y el scutum en Hispania durante la Segunda Edad del Hierro". Boletín del Seminario de Estudios de Arte y Arqueología de la Unviersidad de Valladolid, 6, 57-83.

ChAPA BRUnet, T. (1986) Influjos griegos en la escultura zoomorfa ibérica. Madrid.

Coll, N.; Garcés, I. (1998) "Los últimos príncipes de Occidente. Soberanos ibéricos frente a cartagineses y romanos". Actas del Congreso Internacional 'Los Iberos, príncipes de Occidente’, 437-446. Barcelona.

Conde Berdos, M.J. (1998) "Estado actual de la investigación sobre la cerámica ibérica pintada de época plena y tardía". REIb 3, 299-335.

Connolly, P. (1981) Greece and Rome at War. London.

Cuadrado Díaz, E. (1982) "Decoración extraordinaria de un vaso ibérico" Homenaje a Saénz de Buruaga, 287296 .
Cuadrado Díaz, E. (1990) "Un nuevo análisis de la crátera ibérica del desfile militar". Homenaje a Jerónimo Molina. Murcia, 131-135.

Domínguez Arranz, A. (1997) "Las acuñaciones ibéricas y celtibéricas de la Hispania Citerior". En C. Alfaro et al. Historia Monetaria de Hispania Antigua. Madrid, 116-193.

EICHBERG, M. (1987) Scutum: die Entwicklung einer italichetruskischen Schildform von den Anfängen bis zur Zeit Caesars. Frankfurt/Paris/N.York P.Lang.

Fantar, M. (1993) Carthage. Approche d'une Civilisation. III. Tunis.

Feugere, M. (1994) Casques antiques. Paris.

García-Gelabert Pérez, M.P.; BlázQuez, J.M. (1987) "Mercenarios hispanos en las fuentes literarias y en la Arqueología". Habis 18-19, 257-270.

García Mauriño, J. (1993) "Los cascos de tipo Montefortino en la Península Ibérica. Aproximación al estudio del armamento de la Segunda Edad del Hierro". Complutum 4, 95-146.

García Rubert, D. (2000) "Un casco de tipo Montefortino localizado en la partida de La Carrova (Amposta, Montsià, Tarragona)". Gladius 20, 171-178.

García y Bellido, A. (1943) "Algunos problemas de arte y cronología ibéricas”. AEspA 50, 78108.

García y Bellido, M.P. (1993) "Origen y función del denario ibérico". Sprachen und Schriften des antiken Mittelmeerraums. Festschrift J. Untermann. Innsbruck, 97-123.

Garcia I Rubert, D. (2000) "Un casco de tipo Montefortino localizado en la partida de La Carrova (Amposta, Montsià, Tarragona)". Gladius 20, 171178.

Giacosa, G. (1973) Uomo e cavallo sulla moneta greca. Milano.

GonzÁlez Wagner, C. (1992) "Tartessos en la historiografía: una revisión crítica”. La colonización fenicia en el sur de la Península Ibérica. 100 años de investigación. Almería, 81-103.

GonzÁlez Wagner, C. (1993) "Metodología de la aculturación. Consideraciones sobre las formas de contacto cultural y sus consecuencias". Homenaje alJ. $M^{a}$ Blázquez, I. Madrid, 445-464.

GonzÁlez Wagner, C. (1994) "Guerra, ejército y comunidad cívica en Cartago”, Homenaje al Prof. Presedo, 825-835. Sevilla.

Gracia Alonso, F. (2002) "Análisis táctico de las fortificaciones ibéricas”. Gladius 20, 131-170

Gracia Alonso, F. (2001) "Sobre fortificaciones ibéri- 
cas. El problema de la divergencia respecto al pensamiento único". Gladius 21, 155-166.

Gracia Alonso, F. (2003) La guerra en la Protohistoria. Héroes, nobles, mercenarios y campesinos. Barcelona.

GraU Mira, I. (1996) "Estudio de las excavaciones antiguas de 1953 y 1956 en el poblado ibérico de La Serreta”. Recerques del Museu d'Alcoi 5, 83-119.

Grau Mira, I. (1998-1999) "Un posible centro productor de cerámica ibérica con decoración figurada en la Contestania". Lucentum 17-18, 75-91.

Griffith, G.T. (1935) The mercenaries of the Hellenistic World. Cambridge. Chicago, reprt. 1984.

GUADAN, A.M. (1979) Las armas en la moneda ibérica. Madrid.

HAnson, V.D. (1991) "Hoplite technology in phalanx battle". V.D. Hanson (ed.) Hoplites. The classical Greek battle experience, 63-84. London\&New York.

HoRvat, J. (1997) "Roman Republican weapons from Smilel in Slovenia". M. Feugère (ed.) L'equipement militaire et l'armement de la République. Journal of Roman Military Equipment Studies 8, 105-120.

Hoyos, D. (2003) Hannibal's Dynasty. Power and politics in the western Mediterranean 247-183 BC. London.

Huss, W. (1993) Los Cartagineses. Madrid.

IsTENIC, J. (2000) "A Roman late republican gladius from the river Ljubljanica (Slovenia)". Arheoloski Vestnik 51, 171182.

IzQuierdo Peraile, I. (1995) "Un vaso ibérico con excepcional decoración pintada procedente de la necrópolis ibérica de Corral de Saus” . Hom. A M. Gil-Mascarell. Saguntum 29, 93-104..

Kalus, L. (1977) "Aspects morphologiques et Techniques des Boucliers Musulmans". Gladius 13, 25-62.

Le Bohec, Y. (1996) Histoire Militaire des Guerres Puniques. Monaco.

LeveCQue, P. (1985) "La guerre a l'êpoque hellénistique". J.P. Vernant (ed.) Problèmes de la guerre en Grèce ancienne, 261-287. Paris.

LORRIO, A.J. (1995) "El armamento de los celtíberos a través de la iconografía monetal". La moneda hispánica. Ciudad y territorio. Anejos AEspA XIV, 75-80. Madrid.

Manti, P.A. (1983) “The cavalry sarissa”, Ancient World 8, 73-80.

Marin Ceballos, M.C. (1983) "Una nueva interpretación de la pátera de Tivissa". XVI CNA, Murcia-Cartagena, 1982, 709-717. Zaragoza.

Mata Parreño, C. (1997) "La ciudad ibérica de Edeta y sus hallazgos arqueológicos”. En C. Aranegui (ed.) Damas y caballeros en la ciudad ibérica. Madrid, 48.

Moreno Hernández, J.J. (2002) "Ifícrates y la infantería ligera griega”. Polis 14, 197-224.

Moret, P. (1996) Les fortifications ibériques de la fin de l'Âge du Bronze à la Conquête romaine. Madrid, Casa de Velázquez.

Moret, P. (2001) "Del buen uso de las murallas ibéricas". Gladius 21, 137-144.

Moscati, S. (ed.) (1991) I Celti. Catalogo della mostra. Milano.

Noguera Celdran, J.M. (2003) "La escultura hispanorromana en piedra de época republicana”. En L. Abad (ed.) De Iberia in Hispaniam. La adaptación de las sociedades ibéricas a los modelos romanos. Alicante, 153-208.

Olmos Romera, R. (1987) "Posibles vasos de encargo en la cerámica ibéreica del Sureste”. AespA 60, 21-42.

Olmos Romera, R. (1992) "El surgimiento de la imagen en la sociedad ibérica”. En R.Olmos (ed.) La sociedad ibérica a través de la imagen. Madrid, 8-32.

Page Del Pozo, V. (1984) Imitaciones de influjo griego en la cerámica ibérica de Valencia, Alicante y Murcia. Iberia Graeca 1, Madrid.

PAllares, R. (1991) "Las relaciones entre las representaciones mitológicas de las páteras de Tivissa y el mundo funerario etrusco". J. Remesal, O. Musso (eds.) La presencia de material etrusco en la Península Ibérica. Barcelona, 587-595.

PICARD, C. y G. (1958) La vie quotidienne à Carthage au temps d'Hannibal'. Paris.

PICARD, O. (1986) "Numismatique et iconographie: le cavalier macédonien". Iconographie Classique et identités regionales. BCH Suppl. XIV, 67-76. Paris.

PijoAn, J. (1911-12) "El vas ibèrich d'Archena". AIEC VIVII, 685-686.

Quesada SAnZ, F. (1992) "El casco de Almaciles (Granada) y la cuestión de los cascos de tipo Montefortino en la Península Ibérica”. Verdolay 4, 65-73.

Quesada SAnZ, F. (1994) "Vías de contacto entre la Magna Grecia e Iberia: la cuestión del Mercenariado". En D. Vaquerizo (coord.) Arqueología de la Magna Grecia, Sicilia y Península Ibérica, 191-246. Córdoba.

Quesada SAnZ, F. (1994b) "Vino, aristócratas, tumbas y guerrero en la cultura Ibérica (ss. V-II a.C.)". Verdolay 6, 99-124.

Quesada SANZ, F. (1997a) El armamento ibérico. Estudio 
tipológico, geográfico, funcional, social y simbólico de las armas en la Cultura Ibérica (siglos VI-I a.C.). I-II. Monographies Instrumentum 3. Montagnac, Eds. Monique Mergoil.

Quesada Sanz, F. (1997b) "Les forces dels antagonistes". En I, Garcés, C. Rovira (eds.) Indibil i Mandoni, reis $i$ guerrers. Lleida, 58-68.

Quesada Sanz, F. (1997c) "Montefortino-type and related helmets in the Iberian Peninsula: a study in arechaeological context". M. Feugère (ed.) L'equipement militaire et l'armement de la République. Journal of Roman Military Equipment Studies 8, 151-166.

Quesada SANZ, F. (1997d) “Gladius hispaniensis: an archaeological view from Iberia”. M. Feugère (ed.) L'equipement militaire et l'armement de la République. Journal of Roman Military Equipment Studies 8, 251270 .

Quesada SANZ, F. (1998) "Aristócratas a caballo y la existencia de una verdadera 'caballería' en la Cultura Ibérica: dos ámbitos conceptuales diferentes”. Actas del Congreso Internacional Los Iberos, Príncipes de Occidente, 169-183 . Barcelona.

Quesada Sanz, F. (1999) "Porcuna, Cástulo y la cuestión del supuesto carácter meseteño, indoeuropeo o céltico de su panoplia: el 'armamento ibérico' como armamento ibérico". II Congreso de Arqueología Peninsular, Zamora 1996, vol. II, 425-434.

Quesada SAnZ, F. (2001) "En torno al análisis táctico de las fortificaciones ibéricas. Algunos puntos de vista alternativos". Gladius 21, 145-154.

Quesada SANZ, F. (2003) "La guerra en las comunidades ibéricas (c. 237-c. 195 a.C.): un modelo interpretativo", A. Morillo, F. Cadiou y D. Hourcade (eds.) Defensa y territorio en Hispania de los Escipiones a Augusto, León/Madrid, 101-156.

Quesada SAnZ, F. (2003b) “¿Espejos de piedra? Las imágenes de armas en las estatuas de los guerreros llamados galaicos". Madrider Mitteilungen 44, 87-112.

Quesada Sanz, F.; García y Bellido, M.P. (1995) "Sobre la localización de Ikale(n)sken y la iconografía de sus monedas". La moneda hispánica. Ciudad y territorio. Anejos AEspA XIV, 65-73.Madrid.

Raev, B.A.; Simonenko, A.V.; Treister, M.J. (1991) "Etrusco-Italic and Celtic Helmets in Eastern Europe". JRGZM 38.2, 465-496.

RANDSBORG, K. (1995) Hjortspring. Warfare and sacrifice in Early Europe. Aarhus.

Rapin, A. (2001) "Un bouclier celtique dans la colonie grecque de Camarina (Sicile). Germania 79, 273296.
RAPIN, A. (2001b) "Des épées romaines dans la collection d'Alise-Sainte-Reine”. Gladius 21, 31-56.

Ribera LACOMBA, A. (1995) "La primera evidencia arqueológica de la destrucción de Valentia por Pompeyo". Journal of Roman Archaeology 8, 1940.

Robinson, R.R. (1975) The armour of Imperial Rome. London.

Rouillard, P. (1997) Antiquités de l'Espagne. Paris,

Rovira Hortala, M.C. (1999) "Las armas-trofeo en la Cultura Ibérica: pautas de identificación e intepretación”. Gladius 19, 13-32.

Santosousso, A. (1997) Soldiers, citizens and the symbols of war. From Classical Greece to Republican Rome 500-167 $B C$. Boulder.

SCHAAFF, U. (1988) "Etruskisch-Römische Helme". Antike Helme. Sammlung Lipeperheide und andere bestände des Antikenmuseums Berlin. Mainz, 318-326.

Seco Serra, I.; De La Villa, J. (2003) "Fuentes literarias antiguas sobre los caballos en Hispania". F. Quesada, M. Zamora (eds.) El caballo en la antigua Iberia, 125-140. Madrid.

SEKUndA, N. (1989) "Hellenistic Warfare". En J.Hackett (ed.) Warfare in the Ancient World, 130-135. London.

Sekunda, N. (1994) The Seleucid Army 168-145 BC. Stockport.

Sekunda, N. (1995) The Ptolemaic Army under Prolemy VI Philometor. Stockport.

SEKunda, N. (2001) Hellenistic Infantry Reforms is the 160's $B C$. Lodz.

Smit, Z.; Pelicon, P. (2000) "Analysis of copper alloy fitments on a Roman gladius from the river Ljubljanica”. Arheoloski Vestnik 51, 183187.

SNODGRASs, A. (1964) Early Greek Armour and Weapons from the end of the Bronze Age to 600 BC. Edinburgh.

SNOdgrass, A. (1070) Arms and armour of the Greeks. London.

SoEIro, T. (1980) "Objectos em bronze do castro de Alvarelhos". Gallaecia 6, 637-643.

Stary, P. (1981) "Ursprung und Ausbreitung der eisenzeitlichen Ovalschilde mit spindelförmingem Schildbuckel”. Germania 59, 287306.

STARY, P. (1982) "Keltische Waffen auf der Iberischen Halbinsel”. Madrider Mitteilungen 23, 114-144.

Stead, I.M.; Meeks, N.D. (1996) "The Celtic Warrior Fibula". The Antiquaries Journal 76, 1-16.

TARn, W.W. (1930): Hellenistic Military and Naval Developments. Reimpr. Chicago, Aress Publishers (1984). 
Tortosa Rocamora, T. (1996) "Las primeras representaciones figuradas sobre cerámica en la zona murciana”. En R. Olmos, P. Rouillard (eds.) Formes archä̈ques et arts ibériques. Madrid, 129-149.

Vicente, J.; Punter, M.P.; Ezquerra, B. (1997) “La catapulta tardo-republicana y otro equipamiento militar de 'La Caridad' (Camnireal, Teruel)". $M$. Feugère (ed.) L'equipement militaire et l'armement de la République (Ive-Ier s. Avant J.C.; JRMES 8, 167-199.
Villaronga, L. (1994) Corpus Nvmmom Hispaniae ante Augusti aetatem. Barcelona.

Völling, Th. (1997) "Römische Militaria in Griechenland: ein Überblick". M. Feugère (ed.) L'equipement militaire et l'armement de la République. Journal of Roman Military Equipment Studies 8, 91-103.

YAlicheV, S. (1997) Mercenaries of the Ancient World. London. 